\title{
Clarification of human blood ILC subtype interrelatedness and discovery of amphiregulin production by human NK cells shed light on HIV-1 pathogenesis
}

Yetao Wang ${ }^{1}$, Lawrence Lifshitz ${ }^{1}$, Noah J. Silverstein ${ }^{1}$, Esther Mintzer², Kevin Luk², Pam

St. Louis ${ }^{3}$, Michael A Brehm³, Scot A. Wolfe ${ }^{2}$, Steven G. Deeks ${ }^{4}$, and Jeremy $\operatorname{Luban}^{1,5,6,7,8 *}$

${ }^{1}$ Program in Molecular Medicine, University of Massachusetts Medical School, Worcester, MA, USA

${ }^{2}$ Department of Molecular, Cell and Cancer Biology, University of Massachusetts

Medical School, Worcester, MA, USA

${ }^{3}$ Diabetes Center of Excellence, University of Massachusetts Medical School, Worcester, MA, USA

${ }^{4}$ Department of Medicine, University of California, San Francisco, CA, USA

${ }^{5}$ Department of Biochemistry and Molecular Pharmacology, University of Massachusetts

Medical School, Worcester, MA, USA

${ }^{6}$ Broad Institute of Harvard and MIT, Cambridge, MA, USA

${ }^{7}$ Massachusetts Consortium on Pathogen Readiness, Boston, MA, USA

${ }^{8}$ Lead contact

*Correspondence: jeremy.luban@umassmed.edu 


\section{Abstract}

Human blood innate lymphoid cells (ILCs), which include ILCs and natural killer (NK) cells, derive from a common CD117 ILC precursor (ILCP). Yet, the relationship among the ILC subsets remains unclear. Bulk and single cell RNA-Seq and ATAC-Seq showed that blood ILC subsets cluster into ILC2s, ILCPs, a mixed cluster of CD56 dim and CD56-

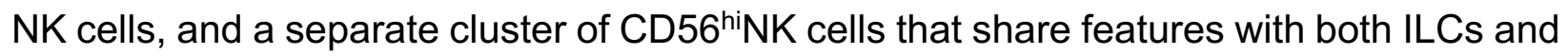
CD56 dim NK cells. In surprising contrast to mice, tissue repair protein amphiregulin was produced by human NK cells, with higher levels in CD56 hiNK cells than in ILCs. Amphiregulin production by human NK cells was promoted by TCF7/WNT signaling and inhibited by TGFB1, a cytokine elevated in people living with HIV-1. Knockout of RUNX3, a WNT antagonist downstream of TGFB1, increased amphiregulin production in human NK cells. CD4 ${ }^{+} \mathrm{T}$ cell depletion in people living with HIV-1, or from PBMCs in tissue culture, was associated with expansion of metabolically inert, nonfunctional CD56-NK cells. Experiments in tissue culture and in humanized mice revealed that CD56-NK cells are derived from CD56 dim NK cells, and that CD4 ${ }^{+} \mathrm{T}$ cell-derived IL-2 stimulates MTOR activity in CD56 ${ }^{\text {dim NK }}$ cells to prevent this transition. These findings clarify how ILC subsets are related to each other and provide insight into how HIV-1 infection disrupts ILC homeostasis and contributes to pathology. 


\section{INTRODUCTION}

Innate lymphoid cells (ILCs) are a diverse population of cells which contribute to a broad range of biological functions, including tissue homeostasis and repair, inflammation, and protection from infection (Barrow and Colonna, 2019; Ebbo et al., 2017; Klose and Artis, 2016). All ILCs bear the leukocyte common antigen CD45, but lack markers of wellcharacterized cellular lineages, including $T$ cells, B cells, hematopoietic stem cells, mast cells, and myeloid cells (Hazenberg and Spits, 2014; Wang et al., 2020; Yudanin et al., 2019).

CD127, the cell surface protein IL-7R $\alpha$ encoded by IL7R, defines a heterogeneous subset of cytokine-producing ILCs, with developmental and functional parallels to CD4 ${ }^{+}$ helper T cells (Artis and Spits, 2015; Cherrier et al., 2018). Specifically, ILC1s are analogs of $T_{H} 1$ cells, which are defined by the transcription factor TBX21, and produce IFN- $y$. Similar to $\mathrm{T}_{\mathrm{H}} 2$ cells, ILC2s are defined by GATA $3^{+}$, bear cell surface marker $\mathrm{CRTH}^{+}$, and produce IL-4, IL-5, and IL-13. ILC3s are counterparts of $\mathrm{T}_{H} 17$ cells, which express RORYT and produce IL-17 and IL-22.

Natural killer (NK) cells are a subset of ILCs, more akin to $\mathrm{CD} 8^{+} \mathrm{T}$ cells in that they have granzyme and perforin-mediated cytolytic activity against tumor cells, and virusinfected cells (Artis and Spits, 2015; Cherrier et al., 2018). NK cells bear proteins that distinguish them from the other ILCs, including CD56, CD16, and the transcription factor EOMES (Artis and Spits, 2015; Cherrier et al., 2018; Spits et al., 2016; Wang et al., 2020).

Despite diversity in gene expression, protein production, and phenotype, all human ILC subsets can be generated experimentally from a common innate lymphoid cell precursor (ILCP) found in the blood (Lim et al., 2017). Consistent with shared derivation from a common precursor, the canonical markers described above do not always discriminate between the ILC subsets. For example, unlike the vast majority of CD56 ${ }^{\text {dim NK }}$ cells, CD56 ${ }^{\text {hi NK }}$ cells bear CD127, CD117, and TCF7 (Wang et al., 2020), proteins typical of ILCs. Additionally, cytokines found in specific environments can reveal phenotypic and functional plasticity in ILCs. CD127 on ILC2s is downregulated by IL-33 in murine lung, mediastinal lymph node, and spleen (Li et al., 2017), or when human blood ILCs are incubated in vitro with common y chain cytokines (Wang et al., 2020). NK cells 
are commonly distinguished from ILCs based on expression of EOMES, but this is not absolute (Bal et al., 2020; Colonna, 2018); TGF- $\beta$ in the salivary gland suppresses EOMES and promotes the ILC-associated genes TNFSF10 and CD73 (Cortez et al., 2016, 2017). Incubation of $\mathrm{Lin}^{-} \mathrm{CD} 34^{-} \mathrm{CD}^{+} 6^{+} \mathrm{CD} 117^{+}$cells from human tonsil with IL-7 and FLT3L, in the presence of OP9-DL1 feeder cells, generates a mixture of CD94 ${ }^{+} \mathrm{NK}$ cells and NKp44+ILC3s (Chen et al., 2018).

Perturbation of ILC and NK cell subsets has been reported in association with Crohn's disease, psoriasis, chronic obstructive pulmonary disease, non-small cell lung cancer, or infection with any of several viruses, including human immunodeficiency virus type 1 (HIV-1), human cytomegalovirus (HCMV), hepatitis C virus (HCV), and influenza A virus (Bal et al., 2020; Lugli et al., 2014; Wang et al., 2020). People living with HIV-1 have permanent depletion of ILC2s in the blood, and of ILC3s in the intestinal lamina propria, even after viremia has been suppressed by antiviral therapy (Kløverpris et al., 2016; Monticelli et al., 2015; Wang et al., 2020).

CD56 ${ }^{\text {hiNK }}$ cells are increased in the blood of people living with HIV-1 or HCV, and in people with systemic lupus erythematosus (Poli et al., 2009; Wang et al., 2020), presumably as a result of chronic inflammation. The numbers of a functionally-defective $\mathrm{Lin}^{-} \mathrm{CD}^{-}{ }^{-} \mathrm{CD} 16^{+} \mathrm{NK}$ cell subset are also expanded by viral infection (HIV-1, HCV, HCMV, and hantavirus), or by autoimmune disease (Björkström et al., 2010; Lugli et al., 2014;

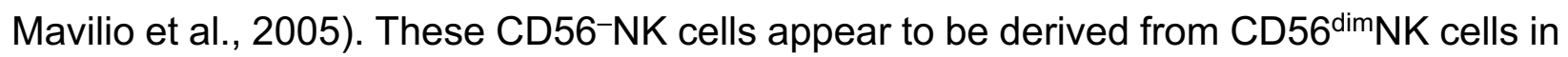
that the expansion of CD56-NK cells is accompanied by a decrease in CD56 ${ }^{\text {dim NK cells }}$ (Björkström et al., 2010; Lugli et al., 2014; Mavilio et al., 2005), and when CD56-NK cells from people with untreated HIV-1 infection are incubated ex vivo with exogenous IL-2, CD56 becomes detectable, though cytolytic function is not restored to the level of CD56 ${ }^{\mathrm{dim}}$ cells (Mavilio et al., 2005).

Taken together, these observations concerning human blood ILCs and NK cells, under conditions of normal homeostasis and in the context of pathogenic inflammation, indicate that much remains to be clarified regarding the relationship between these cell types. Here, global transcriptional and chromatin profiling was used to investigate the relationships between blood ILC and NK cell subsets, and the functional deviations of these cells in people living with HIV-1 infection. These studies provide new insight into 
bioRxiv preprint doi: https://doi.org/10.1101/2021.04.20.440368; this version posted June 8, 2021. The copyright holder for this preprint (which was not certified by peer review) is the author/funder, who has granted bioRxiv a license to display the preprint in perpetuity. It is made available under aCC-BY-NC-ND 4.0 International license.

the relationship between these innate lymphoid cell types and revealed previously unappreciated functions of NK cells. 


\section{RESULTS}

\section{CD127 and CD56 identify four discrete cell populations among Lin $^{-}$human PBMCs}

Steady state human blood innate lymphoid cell populations are composed of $\mathrm{Lin}^{-}$ CD127 ${ }^{+}$CD56- ILCs and Lin ${ }^{-C D 127-C D 56+}{ }^{+}$NK cells (Bal et al., 2020; Hazenberg and Spits, 2014; Wang et al., 2020). However, Lin-CD127-CD56- cells distinct from ILCs are often apparent (Figure 1A). To better characterize this population, and to clarify its relatedness to ILCs, $\mathrm{Lin}^{-} \mathrm{CD} 45^{+} \mathrm{CD} 56^{-}$peripheral blood mononuclear cells (PBMCs) from five healthy donors were sorted into $\mathrm{CD} 127^{-}$and $\mathrm{CD} 127^{+}$subpopulations, and each was subjected to bulk RNA-Seq (Figure 1A and S1A). 401 and 241 differentially expressed genes (DEgenes) were enriched among the CD127- and CD127 ${ }^{+}$cells, respectively (Figure 1B and Table S1).

Consistent with previous reports (Lim et al., 2017; Wang et al., 2020), the LinCD $45^{+} \mathrm{CD} 56^{-} \mathrm{CD} 127^{+}$blood cells were enriched for genes specific to ILC2s, or shared with ILCPs, including IL7R (CD127), IL4R, PTGDR2 (CRTH2), CCR6, CCR7, GATA3 and TCF7, and gene ontology (GO) analysis highlighted expressed genes associated with cytokine production (Figure 1C,1D and Table S1; adjusted $p$ value cut-off $<0.01$ ).

The $\mathrm{Lin}^{-} \mathrm{CD} 45^{+} \mathrm{CD} 56^{-} \mathrm{CD} 127^{-}$population was enriched for mRNAs typical of NK cells: TBX21, EOMES, IFNG, KLRD1 (CD94), 2B4 (CD244), FCGR3A, GZMB, GZMH, GNLY, KIR2DL3, KIR2DL4, KIR2DS4, KIR3DL1, KIR3DL2, and KIR3DL3 (Figure 1C and Table S1). SEMA4D regulates NK cell killing activity and IFN-y production through interaction with CD72 on target cells (Eriksson et al., 2012; He et al., 2017; Kumanogoh and Kikutani, 2004; Mizrahi et al., 2007), and the SEMA4D signaling components, ARHGEF12, ERBB2, RHOC, and MYL9, were well expressed on these cells (Figure 1E and Table S1), as were NK cell-specific receptors, killer Ig-like receptors (KIRs), CD94NKG2C, and NKp44, that use DAP12 as a signal transduction element (Lanier, 2009; Turnbull and Colonna, 2007) (Figure 1E and Table S1). TBX21 and CD16 proteins were detected by flow cytometry on the majority of Lin-CD45 ${ }^{+} \mathrm{CD} 56^{-} \mathrm{CD} 127^{-}$cells, confirming that, despite undetectable CD56 protein, this population consists of bona fide NK cells, a rare cell type in steady state that expands in chronic inflammatory conditions such as HIV- 
1 and HCV infection (Björkström et al., 2010; Lugli et al., 2014; Mavilio et al., 2005) (Figure $1 \mathrm{~F}$ and $1 \mathrm{G})$.

Taking together the transcriptional profiling and flow cytometry analysis, LinPBMCs can be divided into four main ILC subsets, CD56 ${ }^{\text {hi } N K}$ cells, CD56 dim NK cells, CD56-NK cells, and CD $127^{+} \mathrm{ILCs}$, the latter including $\mathrm{CD} 127^{+} \mathrm{CRTH} 2^{+} \mathrm{ILC} 2 \mathrm{~s}$ and CD127 ${ }^{+}$CRTH2-CD117 ${ }^{+}$ILCPs (Figure. 1F, $1 \mathrm{G}$ and S1B).

\section{Global transcription and epigenetic features of the four ILC subsets in human blood}

To better characterize the four ILC subsets in human blood, PBMCs from four healthy blood donors were sorted into ILCs ( Lin $\left.^{-} \mathrm{CD} 45^{+} \mathrm{CD} 56^{-} \mathrm{CD} 127^{+}\right)$, CD56-NK cells ( Lin $^{-}$ CD45 $\left.{ }^{+} \mathrm{CD} 56^{-} \mathrm{CD} 127^{-} \mathrm{CD} 16^{+}\right), \mathrm{CD}^{\mathrm{dim}} \mathrm{NK}$ cells ( Lin $\left.^{-} \mathrm{CD} 45^{+} \mathrm{CD} 56^{\mathrm{dim}}\right)$, and CD56 ${ }^{\text {hi }} \mathrm{NK}$ cells $\left(\right.$ Lin $\left.^{-} \mathrm{CD} 45^{+} \mathrm{CD} 56^{\mathrm{hi}}\right)$. Each population was then separately subjected to bulk RNA-Seq (Figure S1C).

As compared with ILCs, CD56-, CD56 dim ${ }^{\text {, and CD56 }}{ }^{\text {hi }}$ NK cells exhibited 1,128, 1,236, and 910 DEgenes, respectively (Figure $2 \mathrm{~A}$ and Table S2). In contrast with CD56-

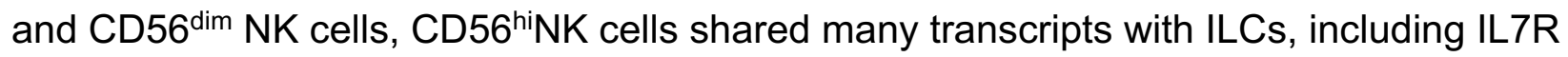
(CD127), KIT, IL4R, IL1RL1 (IL33R), CCR7, GPR183, TCF7, and MYC (Figure S2A and Table S2) (Vivier et al., 2018). Surprisingly, AREG, the gene encoding the epidermal growth factor (EGF)-like amphiregulin that is produced by ILC2s and promotes tissue repair and homeostasis (Zaiss et al., 2015), was expressed in all NK cell subsets, with highest levels in CD56 hi NK cells (Figure 2B and Table S2). In contrast, multiple mouse datasets showed that AREG was expressed by ILC2s, but not by other ILC subsets, nor by NK cells (Figure S2B-S2E and Table S3) (Pokrovskii et al., 2019; Shih et al., 2016; Yoshida et al., 2019), indicating a major difference in AREG regulation between mouse and human.

Principal component analysis confirmed that the human blood ILC transcriptome was distinct from that of all three NK cell subsets, that CD56 dim and CD56- NK cell transcriptomes were nearly indistinguishable from each other, and that the CD56 ${ }^{\text {hi NK cell }}$ transcriptome was distinct from that of the other NK subsets (Figure 2C). 
Reactome analysis showed that, as compared with ILCs, 86 classified pathways were enriched in CD56- and CD56 ${ }^{\text {dim }}$ NK cells, whereas only 8 pathways were enriched in CD56hinK cells (Figure 2D and Table S2). All NK cell subsets, though, were distinguished from ILCs by five pathways, which highlight the fundamental role of IFN-Y and DAP12 signaling in the three NK cell subsets (Figure 2E, S2F and Table S2). Typical of cells with a primary role in secretion of cytokines, the ILCs had high-level expression of genes encoding ribosomal proteins, and proteins involved in translation initiation and elongation (Figure 2F, S2G and Table S2). The ILCs were further distinguished from CD56 ${ }^{\text {hiNK }}$ cells by higher level expression of IL-4, IL-13, and SCF-KIT pathways, consistent with the established functions of ILC2s and ILCPs (Figure 2G, S2H and Table S2).

The global transcriptional profiles of the ILCs and NK cell subsets were mirrored by the chromatin accessibility of genes, as determined by ATAC-Seq. DAP12, GNLY, EOMES, TBX21, NKG7, ILR2B, and CST7 loci were more accessible to Tn5 transposase in NK cell subsets, whereas IL13, IL17RB, PTGDR2, TNFRSF25, SOCS3, IL23A, and IL32 loci were more accessible in ILCs (Figure 2H and S3A). The IL7R promoter was open in both ILCs and CD56 hiNK cells, but not in CD56 $\mathrm{dim} /-$ NK cells, and the AREG promoter was accessible in all NK subsets, as well as in ILCs (Figure 2H). In contrast to these results with human cells, the mouse Areg promoter was only accessible in mouse ILC2s, but not in other ILC subsets or in NK cells (Figure S3B). Interestingly, despite undetectable RORYT protein in blood ILCs (Figure 1G), which are primarily ILC2s in phenotype, the chromatin at the RORC promoter was open (Figure S3A), consistent with the phenotypic plasticity of these cells and their potential to acquire an ILC3 phenotype (Lim et al., 2017).

\section{Single cell transcriptional analysis of human blood ILCs and NK cells}

To clarify the relationship among different ILC subsets, PBMCs from three healthy blood donors were sorted into ILCs $\left(\mathrm{Lin}^{-} \mathrm{CD} 45^{+} \mathrm{CD} 566^{-} \mathrm{CD} 127^{+}\right)$, CD56-NK cells ( $\mathrm{Lin}^{-}$

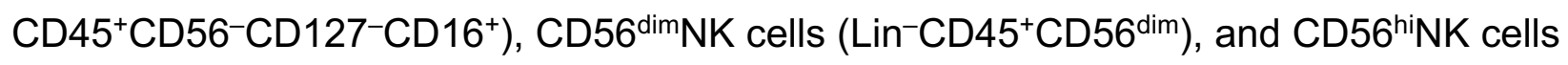
( Lin $^{-} \mathrm{CD} 45^{+} \mathrm{CD}^{\mathrm{hi}}{ }^{\mathrm{hi}}$. Equal numbers of each subset were pooled and subjected to single cell RNA-Seq (Figure S1C). Transcriptomes from 5,210 individual cells were analyzed, 
and $96 \%$ of the cells fit within one of four main clusters (Figure $3 \mathrm{~A}$ ), though surprisingly, not the same four subsets that had been sorted.

$\mathrm{Lin}^{-} \mathrm{CD} 45^{+} \mathrm{CD}^{-} 6^{-} \mathrm{CD} 127^{+}$cells formed two distinct clusters. Cluster one was enriched for expression of genes that define ILC2s, including IL7R (CD127), TCF7, PTGDR2 (CRTH2), GATA3, IL2RA, TNFRSF25, LTB, IL17RB (Figure 3B-3E and Table S4). GATA3-AS1, a gene which increases transcription of IL-5, IL-13, and GATA3(Gibbons et al., 2018), was also enriched in this cluster, as were HPGD and HPGDS, genes encoding prostaglandin D2 biosynthetic enzymes required for ILC2 cytokine production (Figure 3C-3E) (Maric et al., 2019).

Cluster two lacked critical ILC2-associated transcripts, and had higher expression of TNFRSF4 and TNFRSF18, defining features of ILCPS (Lim et al., 2017). FOS, JUN, and JUNB, genes required for cell survival, proliferation, and development (Shaulian and Karin, 2001), were also enriched in this ILCP cluster (Figure 3C-3E and Table S4).

Cluster three was defined as CD56 ${ }^{\text {hiNK }}$ cells, based on expression of GZMK (Wang et al., 2020), and on enrichment for transcripts from both NK cells and ILCs, including TBX21, KLRD1, IL7R, LTB, GATA3, and TCF7 (Figure 3B-3E and Table S4). Consistent with the PCA analysis of bulk RNA-Seq data (Figure 2C), cluster four consisted of both CD56 ${ }^{\mathrm{dim}}$ and CD56- NK cells, despite the fact that the two subsets had been separated by flow cytometry based on CD56 positivity. The CD56 ${ }^{\mathrm{dim} /-}$ cluster was distinguished from CD56 ${ }^{\text {hiNK }}$ cells by exclusively expressing GZMH, and higher levels of CCL3, CCL4, and CCL5. The NK cell signature genes KLRD1, CMC1, NKG7, and CST7 were shared by the CD56 ${ }^{\text {hi }}$ and CD56 dim/- NK cell clusters (Figure 3B-3E and Table S4) (Crinier et al., 2018). Consistent with bulk RNA-Seq data (Figure S2 and Table S2), AREG mRNA was detected in all four clusters (Figure 3C and Table S4).

Pseudotime analysis (Qiu et al., 2017a; Trapnell et al., 2014) was used to determine how the four clusters of blood ILCs are related to each other. ILCs and ILCPS formed one branch, and CD56- and CD56 ${ }^{\mathrm{dim}}$ NK cells formed a second distinct branch (Figure 3F). ETS1, ID2, IKZF1, and IL2RG, genes essential for ILC and NK cell development (Barton et al., 1998; Walker et al., 2013; Zook et al., 2016), were expressed along the full trajectory from ILCs/ILCPs to CD56 $\mathrm{dim} /-\mathrm{NK}$ cells (Figure 3G). Consistent with CD56 ${ }^{\text {hiNK }}$ cells exhibiting epigenetic and transcriptional features of both ILCs (IL7R, KIT, 
IL4R, IL1RL1, CCR7, GPR183, MYC and TCF7), and NK cells (EOMES, TBX21, NCAM1, KLRD1, GZMB, GNLY, and KIRs) (Figure 2 and Table S2), pseudotime analysis placed CD56 ${ }^{\text {hiNK }}$ cells along the trajectory at the junction between ILCs/ILCPs and CD56 $\mathrm{dim} /-\mathrm{NK}$ cells (Figure $3 G$ ), demonstrating that CD56 ${ }^{\text {hi }}$ NK cells occupy an intermediate state between these clusters.

\section{Human blood NK cells are major producers of amphiregulin}

Given the unexpectedly high-level AREG expression in human blood NK cells (Figure 2B and $3 \mathrm{C}$ ), flow cytometry was used to assess cell-associated AREG-encoded protein. Amphiregulin was readily detected in ILCs and all NK subsets after stimulation with PMA and ionomycin (Figure 4A). Whether assessed for mean fluorescence intensity or percent

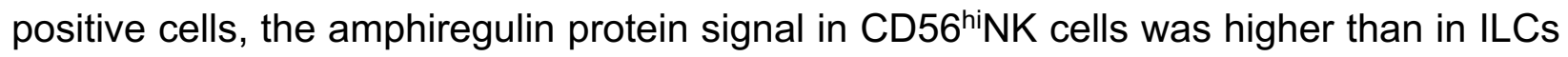
(Figure 4A-4C).

AREG-expressing ILCs maintain tissue homeostasis, and limit the tissue damage that results from inflammation (Monticelli et al., 2011, 2015; Zaiss et al., 2015). People living with HIV-1 infection have reduced numbers of ILCs, and this reduction correlates inversely with systemic inflammation (Wang et al., 2020). Compared with HIV-1individuals, people living with HIV-1 who were not taking antiretroviral therapy (ART) had a decreased percentage of $\mathrm{AREG}^{+}$cells among all NK cell subsets (Figure $4 \mathrm{C}$ ). This was even the case among the controllers who spontaneously maintained viral load below 2,000 copies of HIV-1 gRNA/ml without ART (Figure 4C). In HIV-1 ${ }^{+}$individuals on ART, the percentage of $A R E G^{+}$cells was decreased, but only among CD56hinK cells and ILCs (Figure $4 C$ ). Interestingly, the percentage of $\mathrm{AREG}^{+} \mathrm{NK}$ cells correlated with the frequency of ILCs (Figure 4D), and, in people with viremia, AREG ${ }^{+} N K$ cells correlated with the number of $\mathrm{CD}^{+}{ }^{+} \mathrm{T}$ cells (Figure $4 \mathrm{E}$ ). These results suggest that $\mathrm{AREG}{ }^{+} \mathrm{NK}$ cells play an anti-inflammatory role that prevents disease progression during HIV-1 infection.

CD56 ${ }^{\text {hi NK }}$ cells and ILCs were distinguished from the other NK cell subsets in that they are enriched for expression of TCF7, and other genes in the WNT signaling pathway (Figure S2A and Table S1). The open chromatin region surrounding the AREG promoter (chr4:75,310,271-75,311,679) contains six TCF7-binding sites (Figure 4F). Transcription factor RUNX3, an antagonist of TCF7 and WNT signaling (Ito et al., 2008; Shan et al., 
2017), was expressed at a higher level in all NK cell subsets than in ILCs (Figure 4G), and six RUNX3 binding sites were present in the open chromatin region of AREG (Figure $4 \mathrm{~F}$ ). Consistent with the biological significance of these differences in TCF7 and RUNX3 expression, WNT agonist CHIR99021 upregulated AREG production in NK cells, but not in ILCs (Figure 4H and 4I). Furthermore, TGF- $\beta 1$, which activates RUNX3 signaling and is upregulated during HIV-1 infection (Ikushima and Miyazono, 2010; Ito and Miyazono, 2003; Theron et al., 2017; Wiercińska-Drapalo et al., 2004), attenuated the CHIR99021induced AREG upregulation in NK cells (Figure 4J). Finally, the effect of Cas12a/RNPmediated knockout (Liu et al., 2019) of RUNX3 was assessed in primary blood NK cells from healthy donors. The editing rate for either of two crRNAs was greater than $90 \%$ (Figure S4A, left panel) and, after knockout, RUNX3 protein was undetectable in most of these cells by flow cytometry (Figure S4A, right panel). As compared to cells treated with Cas12a/RNP and a control crRNA targeting the AAVS1, gene editing by either of the two RUNX-specific crRNAs increased AREG production in NK cells (Figure S4B and 4K). These results demonstrate that AREG production in NK cells and ILCs is differentially regulated by TCF7/WNT and RUNX3.

\section{CD56 ${ }^{\text {dim }} \mathrm{NK}$ cells become $\mathrm{CD}^{-} 6^{-}$in the absence of IL-2-producing $\mathrm{CD4}^{+} \mathrm{T}$ cells}

The experiments above demonstrated that the majority of $\mathrm{Lin}^{-} \mathrm{CD} 45^{+} \mathrm{CD} 56^{-} \mathrm{PBMC}$ are ILCs or CD56-NK cells (Figure. 1F). The stability of these innate lymphoid populations can be perturbed by autoimmune diseases or by the inflammation that accompanies viral infection (Bal et al., 2020; Lugli et al., 2014; Wang et al., 2020). In people living with HIV1, ILCs are permanently depleted (Figure 5A) (Kløverpris et al., 2016; Wang et al., 2020) and this reduction correlated inversely with expansion of CD56-NK cells (Figure 5B, S4C and Table S5) (Kløverpris et al., 2016; Wang et al., 2020). However, among people living with HIV-1, CD56-NK cell expansion was greatest in HIV-1 ${ }^{+}$people who were not on ART (Figure 5C, S4D and Table S5) (Mavilio et al., 2005). The close similarity between CD56and CD56 dim NK cells revealed by our cell clustering algorithm (Figure 3), along with the inverse correlation in their numbers (Figure 5D), suggests that CD56 $\mathrm{dim}$ NK cells give rise to CD56-NK cells in the context of HIV-1 infection (Figure S4E). 
To identify an experimental condition in tissue culture under which CD56 ${ }^{\mathrm{dim}} \mathrm{NK}$ cells give rise to CD56- ${ }^{-}$KK cells, and to determine whether a specific cell type among PBMCs stabilizes CD56 dimNK cells, PBMCs from HIV-1- blood donors were maintained in culture for 5 days after selective depletion of either T cells (anti-CD3), CD4 ${ }^{+}$T cells (antiCD4), CD8 ${ }^{+}$T cells (anti-CD8), B cells (anti-CD19 and -CD20), monocytes and macrophages (anti-CD14 and -CD11b), stem cells (anti-CD34), myeloid cells (anti-CD33), or dendritic cells (anti-DC-SIGN and anti-BDCA3). Depletion of CD3 ${ }^{+}$T cells, or of CD4 ${ }^{+} T$ cells, but not of any of the other cell types, increased the proportion of CD56-NK cells among Lin-TBX21+ cells in the cultures (Figure S5A, S5B and 5E). Consistent with this ex vivo experiment, CD56-NK cells were maximally increased in HIV-1 ${ }^{+}$individuals who were not treated with ART, in whom $\mathrm{CD}^{+} \mathrm{T}$ cells were most severely depleted (Figure $5 \mathrm{~F}$ and Table S5). This observation was further supported by the inverse correlation between the numbers of CD56-NK cells and CD4 ${ }^{+} \mathrm{T}$ cells (Figure $5 \mathrm{G}$ ).

Since CD4 ${ }^{+}$T cells maintain NK cell physiology by secreting IL-2 (Jost et al., 2014; Wu et al., 2015), the effect of IL-2 was tested next. Addition of exogenous IL-2 to the PBMC cultures that had been depleted of $\mathrm{CD}^{+} \mathrm{T}$ cells maintained the stability of CD56 dim NK cells, and prevented the increase of CD56-NK cells (Figure $5 \mathrm{H}, 5 \mathrm{I}$ and S5C). The effect of IL-2 was counteracted by anti-IL-2 antibody (Figure 5I, 5J and S5D) or by inhibition of IL-2 signaling by STAT3 or JAK3 inhibitors, but not by STAT6, AKT, or ERK1/2 inhibitors, without compromising cell survival (Figure S5E and S5F). Moreover, TGF- $\beta 1$ which suppresses IL-2 production by $\mathrm{CD} 4^{+} \mathrm{T}$ cells during HIV-1 infection (Das and Levine, 2008; Ikushima and Miyazono, 2010; Ito and Miyazono, 2003; Theron et al., 2017; Wiercińska-Drapalo et al., 2004), increased the percentage of CD56-NK cells and decreased IFN-y production, and exogenous IL-2 counteracted this effect (Figure 5K, 5L).

To test the importance of IL-2 in an in vivo model, NOD-scid II2rgull (NSG) mice reconstituted with human $\mathrm{CD}^{+} 4^{+}$hematopoietic stem cells were injected intravenously with PBS, or with recombinant adeno-associated virus expressing IL-2 (hIL-2-rAAV). 6 weeks later, the ratio of CD56 ${ }^{\mathrm{dim}}$ to $\mathrm{CD}^{-} 6^{-}$NK cells was greater in animals injected with hIL-2-rAAV than in controls (Figure 5M and S5G), and the NK cells from the hIL-2-rAAVtreated mice showed higher IFN-y production than did cells from the control mice (Figure 
$5 \mathrm{~N}$ and $\mathrm{S} 5 \mathrm{H}$ ). Thus, IL-2 is critical for maintaining the physiologically intact CD56 ${ }^{\operatorname{dim}} \mathrm{NK}$ cells in vivo.

\section{Metabolic difference between CD56 ${ }^{\mathrm{dim}}$ and CD56-NK cells}

Comparison of bulk RNA-Seq data from CD56 dim and CD56-NK cells, sorted from healthy donors, revealed that genes associated with immune function (CD6, TRAF3, and IRAK2), and heightened glycolysis and oxidative phosphorylation (NCAM1, MRPL24, ACAT2, B3GAT1, DGKK), were enriched in CD56 dim NK cells (Figure 6A and Table S6) (Poznanski and Ashkar, 2019). Genes regulating transcription, protein modification, and membrane trafficking (TXNDC5, PIGL, GORASP1, ARAP3 and AGAP1) were also enriched in CD56 dim NK cells, whereas genes encoding proteins that inhibit AKT, G-protein signaling, transcription, and NK cell activation and survival (PRMT6, RGS1, ZBTB46, MED20, GNAQ) were enriched in CD56-NK cells (Figure 6A and Table S6).

Upon stimulation with IL-12, IL-15, and IL-18, as compared with CD56-NK cells, CD56 ${ }^{\text {dim NK }}$ cells had greater activation of genes involved in oxidative phosphorylation, translation, membrane trafficking, and immune activation, including DDX19B, RAB9B, RAB39B, TRMT13, GOLGA8B, NDUFAF4P1, COQ4, ACAD8, USP30, PPARGC1B, KLRF1, CXCR6, and STRA13 (Figure 6B and Table S6). Of note, the mitochondrial deubiquitinase USP30, which is important for protecting against depolarization-induced cell death (Liang et al., 2015), was also upregulated by stimulation to a greater extent in

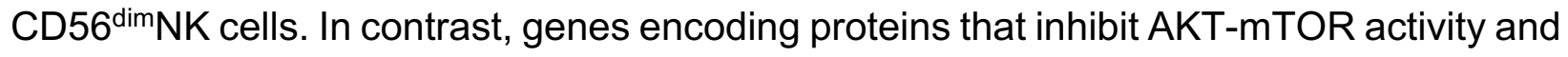
transcription (CITED2 and TSHZ2), and genes associated with fatty acid and cholesterol catabolism (HADH and FDX1), all features of functionally impaired NK cells, were enriched in CD56-NK cells (Figure 6B and Table S6).

The findings above indicate that CD56 ${ }^{\text {dim NK }}$ cells exhibit higher metabolic fitness upon stimulation than do $\mathrm{CD}^{-} 6^{-} \mathrm{NK}$ cells. Consistent with this, multiple activators and targets of mTOR were upregulated, including MAPK6, SREF2, RPS6KA3, TFRC and SLC transporters. mTOR inhibitors, such as CITED2, FOXO3, and GSK3B, were

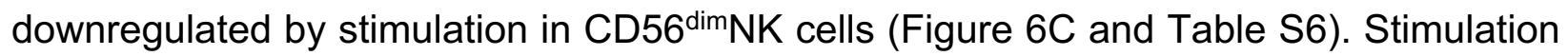
of CD56-NK cells downregulated mTOR activators or targets, such as MAPK3, MAPK13, MAPK14, SLC35A4 and COQ4 (Figure 6C and Table S6). Biological processes that are 


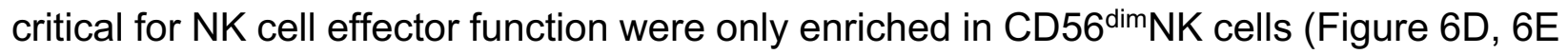
and Table S6).

To better assess the effects of CD4 ${ }^{+} \mathrm{T}$ cells and IL-2 on cultured CD56 ${ }^{\text {dim NK }}$ cells,

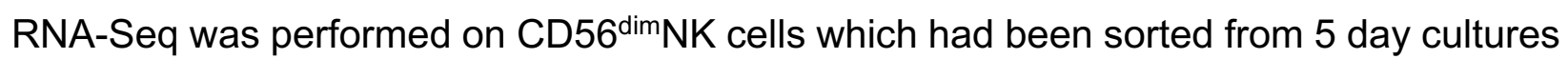
of PBMCs, PBMCs depleted of $\mathrm{CD}^{+} \mathrm{T}$ cells, or PBMCs depleted of $\mathrm{CD} 4^{+} \mathrm{T}$ cells, but supplemented with exogenous IL-2. Gene set enrichment analysis (GSEA) revealed that CD56 dimNK cells from the full PBMC culture, or from the CD4-PBMC culture supplemented with IL-2, but not from the CD4-PBMC culture, were enriched for

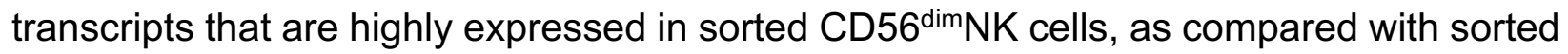
CD56 ${ }^{\text {negNK }}$ cells from PBMC culture (Figure 6F, 6G and Table S7). The convergence of RNA-Seq data from the freshly sorted cells, and the cells cultured under different conditions, indicates that maintenance of metabolically healthy and functional CD56 ${ }^{\operatorname{dim}} \mathrm{NK}$ cells is dependent upon IL-2-producing $\mathrm{CD} 4^{+} \mathrm{T}$ cells.

\section{IL-2 prevents NK cell functional defects caused by mTOR inhibition}

The above results indicate that CD56 ${ }^{\mathrm{dim}}$ and CD56-NK cells have distinct metabolic profiles, with the former having greater mTOR activity (Figure 6). Glycolysis, oxidative phosphorylation, and RNA and protein synthesis, all processes regulated by mTOR signaling, are required for NK cell killing activity and cytokine production (Ganeshan and Chawla, 2014; Poznanski and Ashkar, 2019), and IL-2 induced AKT-mTOR activation is critical for NK cell effector function (Ray et al., 2015; Wu et al., 2017). In fact, IL-2 treatment increased the activity of multiple mTOR components in NK cells, as evidenced by enhanced phosphorylation of mTOR itself on Ser2448, AKT on Ser473, 4EBP1 on Thr36 and Thr45, and S6 on Ser235 and Ser236, and increased surface levels of the transferrin receptor CD71 (Figure 7A), the synthesis of which is known to be positively regulated by mTOR (Zheng et al., 2007). Depletion of $C D 4^{+} T$ cells from cultured PBMCs resulted in downregulation of these markers (Figure 7B), consistent with the role of $\mathrm{CD}^{+} \mathrm{T}$ cells in maintaining metabolic fitness of NK cells (Figure 5E-5I and 6F) .

When mTOR was inhibited by incubating PBMCs in rapamycin, the percentage of CD56-NK cells was increased (Figure 7C and S5I) and IFN-y production of NK cells cultured without $\mathrm{CD}^{+} \mathrm{T}$ cells was decreased (Figure 7D). Moreover, IL-2 treatment 
rescued IFN-y production in the presence of rapamycin (Figure 7D). More potent inhibition by Torin 1 (mTOR kinase inhibitor) led to impaired IFN-Y production by NK cells, even in the presence of $C D 4^{+} \mathrm{T}$ cells; however, this inhibition was overcome by addition to the culture of exogenous IL-2 (Figure 7E). Thus, NK cell functionality is dependent on mTOR, the activity of which is maintained by IL-2-producing CD4 ${ }^{+} \mathrm{T}$ cells.

\section{DISCUSSION}

The bulk RNA-Seq profiling reported here identified four discrete subpopulations of lineage negative cells among human PBMCs: ILC2s, ILCPs, CD56 ${ }^{\text {hiNK }}$ cells, and a distinct cluster which included both CD56 ${ }^{\mathrm{dim}}$ and CD56-NK cells (Figure 2C). Though ILCs and all NK cell subsets were well-separated, CD56hiNK cells shared many features with both ILCs and conventional NK cells (Figure S2A and S2B). Reactome analysis showed that CD56 ${ }^{\text {hiNK }}$ cells share DAP12 signaling with the other NK subsets, as well as translation regulators typical of ILCs (Figure 2E and 2F). Confirming the expression data, ATAC-Seq showed that CD56 ${ }^{\text {hiNK }}$ cells have open chromatin at loci found in both CD56 dim/-NK cells and ILCs (Figure $2 \mathrm{H}$ ). Pseudotime analysis of single cell transcriptome data placed CD56 ${ }^{\text {hiNK }}$ cells at a position between ILCs/ILCPs and CD56 ${ }^{\text {dim/-NK cells }}$ (Figure 3F and 3G). These observations provide new insight into the relationship between human ILCs and NK cells.

An important discovery here was that NK cells express AREG (Figure 4A and 4B), an epidermal growth factor family member that plays important roles in tissue repair and immune tolerance in both mouse models and human disease (Zaiss et al., 2015). Multiple datasets demonstrate that mouse ILC2s express Areg, but that, in mouse NK cells, the Areg locus is closed, and Areg is not expressed (Figure S2B and S3B). Furthermore, unlike in humans, the Areg open chromatin region in mouse ILC2s (chr5: 91,286,257$91,290,763$ ) does not have TCF7 binding sites (http://jaspar.genereg.net/). The fact that the regulation of this gene is so different between the two species (Figure 4F) may explain why production of this homeostatic protein by NK cells has not been reported before. In fact, AREG expression was even higher in CD56 ${ }^{\text {hiNK }}$ cells than in ILC2s (Figure 4A and 4B). AREG expression by NK cells suggests that, in addition to their well-characterized antiviral function, human NK cells may actively limit tissue damage and inflammation that accompanies immune activation. Such non-immune host defense strategies that promote 
host survival without decreasing pathogen burden have been called disease tolerance (Ayres, 2020; Medzhitov et al., 2012).

The AREG-deficiency described here in NK cells isolated from people living with HIV-1 would be expected to contribute to systemic inflammation and increase the risk of cardiovascular disease and cancer in these individuals (Deeks et al., 2013). Elevated TGF- $\beta 1$ has been associated with non-AIDS inflammatory disorders (Theron et al., 2017) and the locus-specific chromatin assays performed here showed that TGF- $\beta 1$-RUNX3 signaling negatively regulates AREG expression in NK cells (Figure 4J and 4K). Perhaps these effects on AREG expression explain in part the persistence of inflammation in this TGF- $\beta 1$-induced immunosuppressive environment.

In people living with HIV-1, AREG ${ }^{+} \mathrm{NK}$ cells were not only decreased in viremic individuals, but also in spontaneous controllers (Figure 4C). In light of this observation, it is interesting that elite controllers experience more frequent hospitalizations for non-AIDS inflammatory complications than do HIV $-1^{+}$people on ART (Crowell et al., 2015). Though many people in the spontaneous controller group studied here do not satisfy the strict criteria required to be labeled as elite controllers, the reduction in $\mathrm{AREG}^{+} \mathrm{NK}$ cells suggests that spontaneous control of viremia comes at the cost of inflammation. Drugs such as CHIR990212, which boost WNT signaling and AREG production by NK cells (Figure $4 \mathrm{H}$ ) might provide benefit to people living with HIV-1 by countering HIV-1associated inflammation.

Previous studies suggest that the numbers of CD56-NK cells increase in people with active HIV-1 replication at the expense of CD56 dim NK cells (Björkström et al., 2010; Mavilio et al., 2005). However, the mechanism behind this shift towards a functionally defective NK cell population required further qualification. To mimic the $\mathrm{CD}^{+} \mathrm{T}$ cell depletion caused by HIV-1 in vivo, CD4 ${ }^{+} \mathrm{T}$ cells were depleted from PBMCs cultured ex

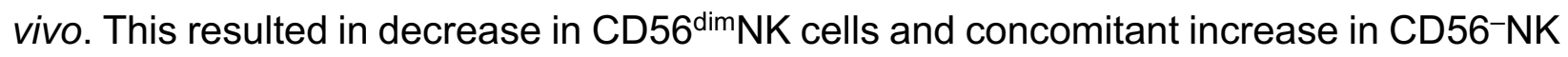
cells (Figure 5E, 5H and S5B). In this experimental system, the basal levels of IL-2 secretion by the $\mathrm{CD} 4^{+} \mathrm{T}$ cells maintained stable numbers of CD56 ${ }^{\text {dim NK }}$ cells, since exogenous IL-2 was sufficient to replace CD4 ${ }^{+} \mathrm{T}$ cells, and IL-2 neutralization rendered $\mathrm{CD}^{+} \mathrm{T}$ cells ineffective (Figure $5 \mathrm{H}-5 \mathrm{~J}$ ). Humanized mice treated with hIL-2-rAAV exhibit higher CD56 ${ }^{+} \mathrm{NK}$ cells in the blood, spleen and liver, and elevated IFN-Y production than 
their counterparts, indicating that IL-2 plays a critical role in maintaining NK cell homeostasis and function (Figure $5 \mathrm{M}$ and $5 \mathrm{~N}$ ).

As compared to CD56 dim NK cells, CD56-NK cells were defective in multiple metabolic pathways, as evidenced by reduced expression, under both resting and stimulated conditions, of genes involved in glycolysis and oxidative phosphorylation (Figure 6A-6E). In response to stimulation, many $\mathrm{mTOR}$ related genes required for upregulation of RNA and protein synthesis (Table S6), were upregulated in CD56 ${ }^{\operatorname{dim} N K}$ cells, but not in CD56-NK cells (Figure 6C-6E). Given the effect on NK cell subsets of culturing PBMCs in the absence of $\mathrm{CD}^{+} \mathrm{T}$ cells or in the presence of exogenous IL-2 (Figure 6F and 6G), it was particularly interesting that exogenous IL-2 promoted mTOR activity whereas $\mathrm{CD}^{+} \mathrm{T}$ cell depletion inhibited it (Figure $7 \mathrm{~A}$ and $7 \mathrm{~B}$ ). Further, NK cell functional defects caused by pharmacologic inhibition of mTOR were rescued by exogenous IL-2 (Figure 7D and 7E). Gene set enrichment analysis demonstrated that $\mathrm{CD}^{+} \mathrm{T}$ cells and IL-2 are similarly important for maintaining the transcriptional profile of

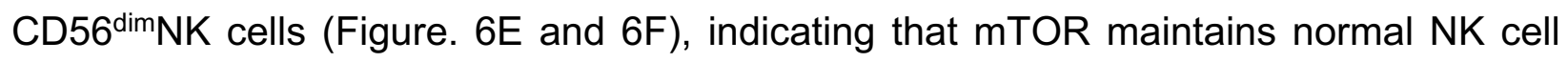
physiology. It has been suggested that mTOR inhibition may serve as an effective intervention to control HIV-1 infection (Besnard et al., 2016; Donia et al., 2010; Heredia et al., 2015; Martin et al., 2017). However, the data obtained here suggests that mTOR inhibition would compromise NK cell effector functions important for viral clearance. 


\section{ACKNOWLEDGEMENTS}

We thank the study participants who provided blood samples and their caretakers. M. Krone (UCSF) provided Institutional Review Board regulatory assistance, sample preparation, and record keeping. S. Maitland provided advice on the purification of programmable nuclease proteins. Ruijia Wang assisted with data analysis. This research was supported by $\mathrm{NIH}$ grants R37Al147868 to J.L., R01HL150669 to S.A.W., R24OD026440, R01Al132963, and UC4DK104218 to M.A.B., F30HD100110 to N.J.S., and F31HL147482 to K.L. The UCSF-based SCOPE cohort was supported by the UCSF/Gladstone Institute of Virology and Immunology CFAR (P30 AI027763), and the CFAR Network of Integrated Systems (R24 Al067039). The content of this publication does not necessarily reflect the views or policies of DHHS, nor does the mention of trade names, commercial products, or organizations imply endorsement by the US Government.

\section{AUTHOR CONTRIBUTIONS}

Y.W. and J.L. designed the experiments. Y.W. performed the experiments with assistance from L.L., N.J.S., E.M., K.L., P.S.L., M.A.B. and S.A.W.. Y.W. and J.L. analyzed the experimental data. Y.W., L.L., N.J.S. and J.L. analyzed the expression data. S.G.D. obtained and provided the clinical samples. Y.W. and J.L. wrote the manuscript, which was revised and approved by all authors.

\section{DECLARATION OF INTERESTS}

M.A.B. is a consultant for The Jackson Laboratory. S.A.W. is a consultant for Chroma Medicine. K.L. and S.A.W. have filed a patent application related to genome editing reagents described in this work. 


\section{FIGURE LEGENDS}

Figure 1. Characterization of Lin- lymphoid cells among human PBMCs.

(A) $\mathrm{CD} 127^{+}$and $\mathrm{CD} 127^{-}$cells from $\mathrm{Lin}^{-} \mathrm{CD} 56^{-}$population after gating on lymphoid, singlet, live, $\mathrm{CD} 45^{+}$cells of PBMCs. Lineage (Lin) markers include antibodies against: CD3, CD4, TCRaß, TCRyठ, CD19, CD20, CD22, CD34, FcعRla, CD11c, CD303, CD123, CD1a, and CD14. (B) Heatmap of differentially expressed genes by RNA-Seq, sorted Lin' CD56-CD 16-CD $127^{+}$versus $\mathrm{Lin}^{-}{ }^{-} \mathrm{CD}^{-} 6^{-} \mathrm{CD} 16^{-} \mathrm{CD} 127^{-}$cells, from PBMCs of five donors (log2 fold change $>1$, padj $<0.01$ determined by DESeq2). (C) normalized counts of Lin $^{-}$ $\mathrm{CD}^{-}{ }^{-} \mathrm{CD} 16^{-} \mathrm{CD} 127^{+}$(red) and $\mathrm{Lin}^{-} \mathrm{CD} 56^{-} \mathrm{CD} 16^{-} \mathrm{CD} 127^{-}$(blue) cells related genes from $B(n=5) .(D, E)$ Reactome analysis based on enriched transcripts of $\mathrm{Lin}^{-} \mathrm{CD} 56^{-} \mathrm{CD} 16^{-}$ CD127 ${ }^{+}$cells (D) or Lin $^{-} \mathrm{CD}^{-} 6^{-} \mathrm{CD} 16^{-} \mathrm{CD} 127^{-}$cells $(\mathrm{E})$. (F) Gating strategy for CD56 ${ }^{\text {hi } N K}$, CD56 dim NK, CD56-NK cells and ILCs. (G) The indicated populations as in F were detected with TBX21, CRTH2 and RORYT. All data were generated using blood from healthy donors. See also Figure S1.

Figure 2. Transcriptional and chromatin accessibility analysis of human blood NK cells and ILCs.

(A) Heatmap of differentially expressed genes by RNA-Seq, sorted CD56 hi NK, CD56 dimNK, CD56-NK cells and ILCs, from PBMCs of 4 donors (log2 fold change $>1$, $p<0.01$ determined by DESeq2). (B) Normalized counts of AREG from (A). (C) PCA based on RNA-Seq data of indicated populations. (D) Number of enriched pathways based on differentially expressed genes of indicated NK subsets versus ILCs by Go Enrichment Analysis. (E) Enriched pathways shared by all NK subsets as compared with ILCs. (F) Shared enriched pathways of ILCs compared with CD56 dim or CD56-NK cells. (G) Enriched pathways of ILCs compared with CD56 hi NK cells. (H) ATAC-Seq analysis of sorted CD56 ${ }^{\text {hi }} \mathrm{NK}, \mathrm{CD} 56^{\text {dim } N K}$, CD56-NK cells and ILCs at indicated gene loci (representative of two donors). All data were generated using blood from healthy donors. See also Figure S2 and S3.

Figure 3. Single cell transcriptome analysis of blood NK cells and ILCs. 
(A) Two-dimensional t-SNE plot of single cell RNA-Seq of sorted CD56 ${ }^{\text {hiNK, CD56 }}{ }^{\text {dimNK, }}$, CD56-NK cells and ILCs. (B, C) Expression and density of the indicated genes within tSNE plots. (D) Heatmap of uniquely higher or lower expressed genes of NK cell or ILC clusters. (E) Representative genes of indicated clusters. (F) Minimum spanning tree based on the transcriptome of individual cells from (A) showing pseudotime trajectory (black line, cells are color coded by clusters). (G) the expression of genes that are enriched by NK cells and/or ILCs along the pseudotime trajectory. All data were generated using blood from healthy donors.

Figure 4. NK cells are major AREG producers among lineage negative PBMCs.

(A) PBMCs were stimulated with PMA and ionomycin for $3 \mathrm{hrs}$ then AREG from different subsets of NK cells and ILCs were detected. (B) The mean fluorescence intensity (MFI) of AREG detected in (A) $(n=20)$. (C) PBMCs from HIV-1- $(n=20)$, HIV-1+ viremic $(n=20)$, HIV-1+ ART suppressed $(n=19)$, and HIV-1 ${ }^{+}$spontaneous controllers $(n=20)$ were stimulated as described in (A) the $\mathrm{AREG}^{+}$cells from indicated populations were detected. (D) Correlation of AREG ${ }^{+} N K$ cells with ILCs $(n=79)$, correlation coefficient $(r)$ by Pearson, zero slope $p$ value determined by the F-test. (E) Correlation of AREG ${ }^{+} N K$ cells with $\mathrm{CD}^{+} \mathrm{T}$ cell numbers in HIV-1+ viremic people $(n=20)$, correlation coefficient $(r)$ by Pearson, zero slope $p$ value determined by the F-test. (F) Schematic map of AREG open chromatin region in NK cells detected by ATAC-Seq, TCF7 and RUNX3 binding motif were predicted by JASPAR motif analysis (http://jaspar.genereg.net/). (G) Normalized counts of RUNX3 by RNA-Seq $(n=4)$. ( $\mathrm{H}, \mathrm{I})$ PBMCs were treated with CHIR99021 (10uM) for 48 hrs, then stimulated as described in (A), the percentage of AREG ${ }^{+} N K$ cells $(H)$ and AREG ILCs $(I)$ were shown $(n=15)$. (J) As in $(H)$, PBMCs were additionally treated with CHIR99021 and TGF- $\beta 1$ before AREG ${ }^{+} N K$ cells were detected $(n=8)$. (K) AREG ${ }^{+} N K$ cells were detected after IL-12+IL-15+IL-18 stimulation for $16 \mathrm{hrs}$ from control or RUNX3 knockout groups $(n=4)$. Data are mean \pm s.e.m., $(B, G-K)$, two-tailed paired $t$-test. $(C)$, two-tailed unpaired $t$-test. ns, not significant, ${ }^{*} p<0.05,{ }^{* *} p<0.01,{ }^{* *} p<0.001$. For $(A, B, G-K)$ data were derived from healthy donors. For (C-E), cohort was described in Table S5. See also Figure S4.

Figure 5. $\mathrm{CD}^{+}{ }^{+} \mathrm{T}$ cell depletion destabilizes NK cells. 
(A) Percentage of ILCs from Lin-CD56- population. HIV-1- $(n=40)$, HIV-1 ${ }^{+}$viremic $(n=40)$, HIV- $1^{+}$ART suppressed ( $\left.n=37\right)$, and HIV-1 ${ }^{+}$spontaneous controllers $(n=40)$. (B) Correlation of ILCs and CD56-NK cells in $\mathrm{Lin}^{-}{ }^{-} \mathrm{CD}^{-} 6^{-}$population from (A). (C) Percentage of CD56 ${ }^{-}$and CD56 ${ }^{\text {dim }}$ NK cells in total NK cells in indicated groups ( $n=40$ for each group). (D) Correlation of CD56- and CD56 dim NK cells from (C). (E) Percentage of CD56-NK cells in total NK cells were detected from PBMCs and CD4-PBMCs after culture for 5 days $(n=7)$. (F) CD4 ${ }^{+} T$ cell number (counts $/ \mathrm{mm}^{3}$ ) from indicated groups ( $\mathrm{n}=40$ for each group). (G) Correlation of CD4 number and CD56-NK cells $(n=160)$. (H) Detection of CD56 dim and CD56- NK cells after culture for 5 days in indicated conditions. (I) Percentage of CD56NK cells in total NK cells was detected from CD4-PBMCs in the presence or absence of IL-2 (10ng/ml) combined with or without IL-2 neutralizing antibody $(4 \mathrm{ug} / \mathrm{ml})(\mathrm{n}=7)$. (J) Percentage of CD56-NK cells in total NK cells was detected from PBMCs after treatment with isotype or IL-2 neutralizing antibody $(4 \mathrm{ug} / \mathrm{ml})$ for 5 days $(n=10)$. (K, L) Percentage of CD56-NK $(K)$ or IFN- $\gamma^{+}$NK $(L)$ cells in total NK cells was detected from PBMCs after treatment with TGF- $\beta 1(50 \mathrm{ng} / \mathrm{ml})$ or TGF- $\beta 1(50 \mathrm{ng} / \mathrm{ml})+\mathrm{lL}-2(20 \mathrm{ng} / \mathrm{ml})$ for 5 days $(n=8)$. $(\mathrm{M}, \mathrm{N}) \mathrm{NSG}$ mice reconstituted with human $\mathrm{CD} 34^{+}$hematopoietic stem cells were injected intravenously with PBS $(n=5)$ or with hIL-2-rAAV $(n=4), 6$ weeks later, the blood, spleen and liver were harvested for detection of CD56 (K) or IFN- $\gamma$ production $(L)$ from human NK cells. Data are mean \pm s.e.m., $(A, C, F, M, N)$, two-tailed unpaired $t$-test. $(E, I-L)$, twotailed paired $t$-test. ns, not significant, ${ }^{*} p<0.05,{ }^{* *} p<0.01,{ }^{* * *} p<0.001$. For $(E, H-L)$, data were derived from healthy donors. For (A-D, F-H), cohort was described in Table S5. See also Figure S4 and S5.

Figure 6. CD56 dim NK cells are distinguished from CD56-NK cells by metabolic gene expression.

(A, B) Heatmap of metabolism and immune related genes that differentially express between $\mathrm{CD}^{-} 6^{-}$and $C D 56^{\mathrm{dim}} \mathrm{NK}$ cells directly sorted from PBMCs before $(A, n=4)$ or after IL-12+IL-15+1L-18 stimulation $(B, n=3$ ) (log2 fold change $>1, p<0.01$ determined by DESeq2). (C) Log2 fold change of mTOR signaling related genes of IL-12+IL-15+IL-18 stimulated versus un-stimulated CD56 ${ }^{-}$or CD56 ${ }^{\mathrm{dim}}$ NK cells. ns, not significant, ${ }^{* *} \mathrm{p}<0.01$, ${ }^{* * *} p<0.001$. (D, E) Protein classes analysis of $\mathrm{CD}^{2} 6^{-}$or CD56 ${ }^{\mathrm{dim}} \mathrm{NK}$ cells enriched genes 
after IL-12+IL-15+IL-18 stimulation. (F, G) GSEAs comparing the CD56 dim NK cell expression signature in PBMCs (determined by RNA-seq, CD56 dim versus CD56-NK

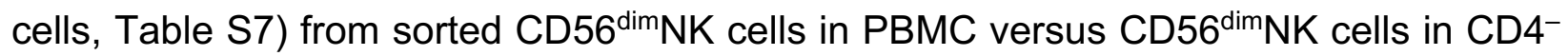
PBMC (F) or CD56 dim NK in CD4-PBMC with IL-2 versus CD56 dim NK in CD4-PBMC (G) after culture for 5 days. All data were generated using blood from healthy donors.

Figure 7. IL-2 overcomes the effects of CD4 ${ }^{+} T$ cell depletion or MTOR inhibition.

(A) PBMCs were cultured with or without IL-2 $(50 \mathrm{ng} / \mathrm{ml})$ for 5 days, the phosphorylation of mTOR on Ser2448, AKT on Ser473, 4EBP1 on Thr36 and Thr45, and S6 on Ser235 and Ser236, and the surface CD71 from NK cells ( in $^{-}$TBX $21^{+}$) were detected by flow cytometry $(n=8)$. (B) PBMCs or CD4-PBMCs were cultured for 5 days, the indicated targets from NK cells were detected as in $(A)(n=8)$. (C) PBMCs were treated with or without rapamycin (10nM) for 5 days, the percentage of CD56-NK cells in Lin-TBX21+ population was detected $(n=7)$. (D, E) PBMCs or CD4-PBMCs were cultured in the presence or absence of rapamycin (10nM) (D) or Torin $1(250 \mathrm{nM})(\mathrm{E})$ combined with or without IL-2 $(10 \mathrm{ng} / \mathrm{ml})$ for 5 days, then were stimulated with IL-12+IL-15+IL-18 for $16 \mathrm{hrs}$, the IFN-y from Lin-TBX21+ population were detected. Data are mean \pm s.e.m., two-tailed paired $t$-test. ns, not significant, ${ }^{*} p<0.05,{ }^{* *} p<0.01,{ }^{* * *} p<0.001$. All data were generated using blood from healthy donors. See also Figure S5. 


\section{Materials and Methods}

\section{Reagent Table}

\begin{tabular}{|c|c|c|}
\hline REAGENT & SOURCE & IDENTIFIER \\
\hline \multicolumn{3}{|l|}{ Antibodies } \\
\hline Anti-Human CD3 & BioLegend & Cat\# 317306 Clone: OKT3 \\
\hline Anti-Human CD4 & BioLegend & Cat\# 317408 Clone: OKT4 \\
\hline Anti-Human TCRa/b & BioLegend & Cat\# 306706 Clone: IP26 \\
\hline Anti-Human TCRg/d & BioLegend & Cat\# 331208 Clone: B1 \\
\hline Anti-Human CD19 & BioLegend & Cat\# 302206 Clone: HIB19 \\
\hline Anti-Human CD20 & BioLegend & Cat\# 302304 Clone: $2 \mathrm{H} 7 \mathrm{a}$ \\
\hline Anti-Human CD22 & BioLegend & Cat\# 363508 Clone: S-HCL-1 \\
\hline Anti-Human CD14 & BioLegend & Cat\# 325604 Clone: HCD14 \\
\hline Anti-Human CD34 & BioLegend & Cat\# 343504 Clone: 581 \\
\hline Anti-Human FceR1 $\alpha$ & BioLegend & Cat\# 334608 Clone: AER-37 \\
\hline Anti-Human CD1a & BioLegend & Cat\# 300104 Clone: HI149 \\
\hline Anti-Human CD11c & BioLegend & Cat\# 301604 Clone: 3.9 \\
\hline Anti-Human CD123 & BioLegend & Cat\# 306014 Clone: $6 \mathrm{H} 6$ \\
\hline Anti-Human BDCA1 & BioLegend & Cat\# 354208 Clone: 201A \\
\hline Anti-Human ROR $\gamma \mathrm{T}$ & ebioscience & Cat\# 12-6988-82 Clone: AFKJS-9 \\
\hline Anti-Human ROR $\gamma \mathrm{T}$ & ebioscience & Cat\# 17-6988-82 Clone: AFKJS-9 \\
\hline Anti-Human TBX21 & ebioscience & Cat\# 25-5825-82 Clone: ebio4B10 \\
\hline Anti-Human CRTH2 & BioLegend & Cat\# 350116 Clone: BM16 \\
\hline Mouse IgG1 k Isotype control & ebioscience & Cat\# 25-4714-80 Clone: P3.6.2.8.1 \\
\hline Rat IgG2a k isotype control & ebioscience & Cat\# 12-4321-80 Clone: eBR2a \\
\hline Rat IgG2a, k isotype control & BioLegend & Cat\# 400532 Clone: RTK2758 \\
\hline Anti-Human IFN- $\gamma$ & BioLegend & Cat\# 502512 Clone: 4S.B3 \\
\hline Anti-Human IFN- $\gamma$ & BioLegend & Cat\# 502509 Clone: 4S.B3 \\
\hline
\end{tabular}




\begin{tabular}{|c|c|c|}
\hline Anti-Human IFN- $\gamma$ & BioLegend & Cat\# 502528 Clone: 4S.B3 \\
\hline Anti-Human AREG & ebioscience & Cat\# 17-5370-42 Clone: AREG559 \\
\hline Anti-Human CD16 & BioLegend & Cat\# 980104 Clone: $3 G 8$ \\
\hline Anti-Human CD45 & BD & Cat\# 560178 Clone: 2D1 \\
\hline Anti-Human CD56 & BioLegend & Cat\# 318306 Clone: HCD56 \\
\hline Anti-Human CD56 & BioLegend & Cat\# 318310 Clone: HCD56 \\
\hline Anti-Human CD56 & BioLegend & Cat\# 318322 Clone: HCD56 \\
\hline Anti-Human CD117 & BioLegend & Cat\# 313213 Clone: 104D2 \\
\hline Anti-Human CD127 & BioLegend & Cat\# 351316 Clone: A019D5 \\
\hline Anti-Human CD127 & BioLegend & Cat\# 351304 Clone: A019D5 \\
\hline Anti-Human CD127 & BioLegend & Cat\# 351320 Clone: A019D5 \\
\hline Anti-Human CD71 & BioLegend & Cat\# 334114 Clone: CY1G4 \\
\hline Anti-Human IL-2 & R\&D & Cat\# MAB202 \\
\hline Mouse IgG1 Isotype Control & R\&D & Cat\# MAB002 \\
\hline Anti-Human pMTOR Ser 2448 & ebioscience & Cat\# 12-9718-42 Clone: MRRBY \\
\hline Anti-Human pAKT Ser 473 & ebioscience & Cat\# 17-9715-42 Clone: SDRNR \\
\hline Anti-Human p4EBP1 Thr 36, 45 & ebioscience & Cat\# 12-9107-42 Clone: V3NTY24 \\
\hline Anti-Human pS6 Ser 235, 236 & ebioscience & Cat\# 12-9007-42 Clone: cupk43k \\
\hline \multicolumn{3}{|l|}{ Biological Samples } \\
\hline PBMCs & $\begin{array}{l}\text { UCSF Medical } \\
\text { Center }\end{array}$ & https://hividgm.ucsf.edu/scope-study \\
\hline PBMCs & $\begin{array}{l}\text { New York } \\
\text { Biologics }\end{array}$ & https://www.newyorkbiologics.com/ \\
\hline \multicolumn{3}{|c|}{ Chemicals, Peptides, and Recombinant Proteins } \\
\hline IL-2 & PeproTech & Cat\# 200-02 \\
\hline
\end{tabular}


bioRxiv preprint doi: https://doi.org/10.1101/2021.04.20.440368; this version posted June 8, 2021. The copyright holder for this preprint (which was not certified by peer review) is the author/funder, who has granted bioRxiv a license to display the preprint in perpetuity. It is made available under aCC-BY-NC-ND 4.0 International license.

\begin{tabular}{|c|c|c|}
\hline IL-12p70 & PeproTech & Cat\# 200-12 \\
\hline IL-15 & PeproTech & Cat\# 200-15 \\
\hline IL-18 & InvivoGen & Cat\# rcyec-hil18 \\
\hline TGF-b & PeproTech & Cat\# 100-21 \\
\hline Rapamycin & Millipore & Cat\# 553211-500UG \\
\hline Torin1 & TOCRIS & Cat\# 4247 \\
\hline CP-690550 & InvivoGen & Cat\# tlrl-cp69 \\
\hline CHIR99021 & TOCRIS & Cat\# 4423 \\
\hline C188-9 & Selleckchem & Cat\# S8605 \\
\hline AS-1517499 & Selleckchem & Cat\# S8685 \\
\hline MK-2206 & Selleckchem & Cat\# S1078 \\
\hline Ravoxertinib & Selleckchem & Cat\# S7554 \\
\hline cell stimulation cocktail & ebioscience & Cat\# 00-4970-03 \\
\hline protein transport inhibitor & ebioscience & Cat\# 00-4980-03 \\
\hline TRIzol reagent & Invitrogen & Cat\# 15596018 \\
\hline $\begin{array}{l}\text { NEBNext Multiplex Oligos for } \\
\text { Illumina }\end{array}$ & NEB & Cat\# E6609S \\
\hline AMPure XP beads & Beckman Culter & Cat\# A63880 \\
\hline enAsCAS12a & $\begin{array}{l}\text { Wolfe Lab } \\
\text { (University of } \\
\text { Massachusetts } \\
\text { Medical school) }\end{array}$ & N/A \\
\hline ExoSAP-IT & Affymetrix & Cat\# 78200 \\
\hline
\end{tabular}




\begin{tabular}{|c|c|c|}
\hline Nextera Tn5 Transposase & Illumina & Cat\# FC-121-1030 \\
\hline SuperScript VILO Master Mix & Invitrogen & Cat\# 11755050 \\
\hline \multicolumn{3}{|l|}{ Critical Commercial Assays } \\
\hline Live and Dead violet viability kit & Invitrogen & Cat\# L-34963 \\
\hline Mycoplasma detection kit & Lonza & Cat\# LT27-318 \\
\hline $\begin{array}{l}\text { NEBNext Ultra II DNA library Prep kit } \\
\text { for Illumina }\end{array}$ & NEB & Cat\# 7645L \\
\hline PCR product purification kit & Promega & Cat\# A9282 \\
\hline $\begin{array}{l}\text { P3 Primary Cell 4D-NucleofectorTM } \\
\text { X Kit S }\end{array}$ & Lonza & Cat\# V4XP-3032 \\
\hline $\begin{array}{l}\text { EasySep Human NK Cell Isolation } \\
\text { Kit }\end{array}$ & STEMCELL & Cat\#17955 \\
\hline NK MACS Medium human & MACS & Cat\# 130-114-429 \\
\hline Single Cell 3' Reagent Kits v2 & 10xGenomics & Cat\# 120234 \\
\hline $\begin{array}{l}\text { NEBNext Ultra II Non directional } \\
\text { Second Strand Synthesis Module }\end{array}$ & NEB & Cat\# E6111L \\
\hline $\begin{array}{l}\text { HiScribe T7 High Yield RNA } \\
\text { Synthesis Kit }\end{array}$ & NEB & Cat\# E2040S \\
\hline \multicolumn{3}{|l|}{ Deposited Data } \\
\hline $\begin{array}{l}\text { Bulk and single cell RNA-Seq, } \\
\text { ATAC-Seq data generated in this } \\
\text { study }\end{array}$ & $\begin{array}{l}\text { NCBI Gene } \\
\text { Expression } \\
\text { Omnibus }\end{array}$ & GSE168212 \\
\hline $\begin{array}{l}\text { Mouse RNA-Seq and ATAC-Seq } \\
\text { generated by previous research }\end{array}$ & $\begin{array}{l}\text { NCBI Gene } \\
\text { Expression } \\
\text { Omnibus }\end{array}$ & GSE77695, GSE109125, and GSE11609 \\
\hline \multicolumn{3}{|l|}{ Software and Algorithms } \\
\hline FlowJo & FlowJo, LLC & https://www.flowjo.com/ \\
\hline
\end{tabular}




\begin{tabular}{|c|c|c|}
\hline GraphPad Prism & $\begin{array}{l}\text { GraphPad } \\
\text { Software, Inc }\end{array}$ & $\begin{array}{l}\text { https://www.graphpad.com/scientific- } \\
\text { software/prism/ }\end{array}$ \\
\hline Cell Ranger & 10xGENOMICS & $\begin{array}{l}\text { https://support.10xgenomics.com/single- } \\
\text { cell-gene- } \\
\text { expression/software/downloads/latest? }\end{array}$ \\
\hline Tophat & Kim et al., 2013 & $\begin{array}{l}\text { https://ccb.jhu.edu/software/tophat/index.s } \\
\text { html }\end{array}$ \\
\hline samtools & Li et al., 2009 & http://www.htslib.org \\
\hline R Statistical Computing Software & $\begin{array}{l}\text { The } R \\
\text { Foundation }\end{array}$ & https://www.r-project.org/ \\
\hline ESAT & Derr et al. 2016 & https://github.com/garber-lab/ESAT \\
\hline DESeq2 & Love et al., 2014 & $\begin{array}{l}\text { https://bioconductor.org/packages/release/ } \\
\text { bioc/html/DESeq2.html }\end{array}$ \\
\hline EdgeR & $\begin{array}{l}\text { Robinson and } \\
\text { Oshlack, } 2010\end{array}$ & $\begin{array}{l}\text { https://bioconductor.org/packages/release/ } \\
\text { bioc/html/edgeR.html }\end{array}$ \\
\hline Rtsne & $\begin{array}{l}\text { Van Der Maaten, } \\
2014\end{array}$ & $\begin{array}{l}\text { https://cran.r- } \\
\text { project.org/web/packages/Rtsne/index.html }\end{array}$ \\
\hline Monocle & $\begin{array}{l}\text { Trapnell et al., } \\
2014\end{array}$ & $\begin{array}{l}\text { https://bioconductor.org/packages/release/ } \\
\text { bioc/html/monocle.html }\end{array}$ \\
\hline Bowtie2 & $\begin{array}{l}\text { Langmead and } \\
\text { Salzberg et al., } \\
2012\end{array}$ & $\begin{array}{l}\text { http://bowtie- } \\
\text { bio.sourceforge.net/bowtie2/index.shtml }\end{array}$ \\
\hline RSEM & $\begin{array}{l}\text { Li and Dewey, } \\
2011\end{array}$ & $\begin{array}{l}\text { https://cran.r- } \\
\text { project.org/web/packages/rsem/index.html }\end{array}$ \\
\hline MACS2 & Zhang et al., 2008 & $\begin{array}{l}\text { https://github.com/macs3- } \\
\text { project/MACS/wiki/Install-macs2 }\end{array}$ \\
\hline IGVTools & $\begin{array}{l}\text { Robinson etal., } \\
2011\end{array}$ & $\begin{array}{l}\text { https://software.broadinstitute.org/software/ } \\
\text { igv/download }\end{array}$ \\
\hline Trimmomatic & Bolger et al., 2014 & https://github.com/usadellab/Trimmomatic \\
\hline STAR & Dobin et al., 2013 & $\begin{array}{l}\text { https://cran.r- } \\
\text { project.org/web/packages/stars/index.html }\end{array}$ \\
\hline JASPAR & JASPAR & http://jaspar.genereg.net/ \\
\hline GSEA & Aravind S, 2005 & $\begin{array}{l}\text { https://genepattern.broadinstitute.org/gp/pa } \\
\text { ges/index.jsf }\end{array}$ \\
\hline Seurat 3.0 & $\begin{array}{l}\text { Sturat and Butler, } \\
2019\end{array}$ & http://satijalab.org/seurat/ \\
\hline
\end{tabular}


Clinical samples. PBMCs of $\mathrm{HIV}-1^{-}, \mathrm{HIV}-1^{+}$viremic, $\mathrm{HIV}-1^{+}$on $\mathrm{ART}$, and $\mathrm{HIV}-1^{+}$, controllers used in this study, were from the University of California San Francisco SCOPE Cohort. The clinical characteristics of each individual in the SCOPE cohort was provided in Table S5. All participants provided written informed consent for protocols that were included in study of cellular immunity in HIV-1 infection, in accordance with procedures approved by the University of Massachusetts Medical School (UMMS), and the University of California, San Francisco (UCSF) Institutional Review Boards. Consent was obtained from all participants the day of the procedure. All PBMCs from the SCOPE cohort were tested blindly with the code broken after analysis, and no samples were excluded from the analysis.

Human mononuclear cell isolation and NK cell enrichment. Human peripheral blood was diluted in equal volume of RPMI-1640 (Gibco), overlaid on Lymphoprep (STEMSELL, 07851), and centrifuged at $500 \times \mathrm{g}$ at room temperature for 30 minutes. Mononuclear cells were washed 3 times with MACS buffer (0.5\% BSA and 2 mM EDTA in PBS), and either used immediately, or frozen in FBS containing 10\% DMSO. NK cells were negatively enriched using EasySep ${ }^{\text {TM }}$ Human NK Cell Isolation Kit (STEMCELL, 17955), according to the manufacturer's instructions.

Flow cytometry. Cells were first stained with Live and Dead violet viability kit (Invitrogen, L-34963). To detect surface molecules, cells were stained in MACS buffer with antibodies for 30 min at $4^{\circ} \mathrm{C}$ in the dark. To detect IFN-y or AREG, cells were stimulated with the IL$12(10 \mathrm{ng} / \mathrm{ml}), \mathrm{IL}-15(50 \mathrm{ng} / \mathrm{ml})$ and IL-18 $(50 \mathrm{ng} / \mathrm{ml})$ for $16 \mathrm{hrs}$, or with PMA and ionomycin (eBioscience, 00-4970-03) for 3 hrs. In both cases, protein transport inhibitors (eBioscience, 00-4980-03) were present during the stimulation. To detect transcription factors or cytokines, cells were fixed and permeabilized using Foxp3 staining buffer kit (eBioscience, 00-5523-00), then intracellular molecules were stained in permeabilization buffer with antibodies.

Sorting of NK cells and ILCs. PBMCs were stained with a panel of lineage markers, CD56, CD16 and CD127. The CD56 ${ }^{\text {hi }}$, CD56 ${ }^{\text {dim }}$, CD56 $^{-}$and ILCs were sorted as indicated 
in Extended Data Fig. 1a and c using a BD FACSAria llu. Enrichment of the sorted cell populations was confirmed by flow cytometry before initiation of downstream experiments.

Bulk RNA-Seq Library preparation. The sequencing library was prepared using CELSeq2 (Hashimshony et al., 2016). RNA from sorted cells was extracted using TRIzol reagent (ThermoFisher, 15596018). $10 \mathrm{ng}$ RNA was used for first strand cDNA synthesis using barcoded primers (the specific primers for each sample were listed in Table S8). The second strand was synthesized by NEBNext Second Strand Synthesis Module (NEB, E6111L). The pooled dsDNA was purified with AMPure XP beads (Beckman Coulter, A63880), and subjected to in vitro transcription (IVT) using HiScribe T7 High Yield RNA Synthesis Kit (NEB, E2040S), then treated with ExoSAP-IT (Affymetrix, 78200). IVT RNA was fragmented using RNA fragmentation reagents (Ambion), and underwent another reverse transcription step using random hexamer RT primer-5'-GCC TTG GCA CCC GAG AAT TCC ANN NNN N-3' to incorporate the second adapter. The final library was amplified with indexed primers: RP1 and RPI1 or RPI2 (as indicated in Supplementary Table 8), and the beads purified library was quantified with 4200 TapeStation (Agilent Technologies), and paired-end sequenced on Nextseq 500 V2 (Illumina), Read 1: 15 cycles; index 1: 6 cycles; Read 2: 60 cycles.

Library preparation for single cell RNA-Seq. The sequencing library was prepared by Single Cell 3' Reagent Kits v2 (10xgenomics, 120234). Isolated cells were 2x washed and resuspended in 1xPBS containing $0.05 \%$ BSA. Cell number and viability were measured by Bio-Rad TC 20 cell counter, cell concentration was adjusted around 10001500 cells/ul (viability>90\%). Single cell suspension was loaded onto Chromium Controller (10xGenomics) to participate $3000-6000$ single cells into gel beads in emulsions (GEMs). Libraries were constructed according to the instruction of single cell 3' reagent kits $v 2$. The yield and the quality of amplified cDNA were checked using High Sensitivity D5000 ScreenTape on TapeStation (Agilent Technologies). The final library was amplified using PCR cycles determined by cDNA quantification, and the quality of the library was checked again by TapeStation. The sequencing depth was controlled at 
more than 50,000 reads per cell. Sorted CD56-, CD56 dim, CD56 ${ }^{\text {hi NK }}$ cells and ILCs from three donors were pooled and were sequenced as one sample, indexed using primers from the B2 position of the index plate.

ATAC-Seq. Nuclei were precipitated after sorted CD56 ${ }^{\text {hi }}$, CD56 ${ }^{\text {dim }}$, CD56- NK cells and ILCs were suspended in lysis buffer (10 mM Tris. $\mathrm{Cl}$, pH 7.4; $10 \mathrm{mM} \mathrm{NaCl} ; 3 \mathrm{mM} \mathrm{MgCl}$, 0.1\% NP-40). 2.5 ul of Tn5 transposase (Nextera DNA Library Prep Kit, Illumina, FC-1211030) was added per $50 \mathrm{ul}$ reaction, for $30 \mathrm{~min}$ at $37^{\circ} \mathrm{C}$. Released DNA fragments were purified by PCR product purification kit (Promega, A9282) and used to generate libraries. The barcode primers and common primers used for each sample from 2 donors were listed in Table S8. Libraries were paired-end sequenced on Nextseq 500 V2 (Illumina) using Read 1: 42 cycles; Index 1: 8 cycles, and Read 2: 42 cycles.

Bulk RNA-Seq Processing and Analysis. The pooled reads were separated by CELSeq2 barcodes and mapped to the hg19 genome using Tophat (Kim et al., 2013) (version 2.0.14, default parameters). ESAT (Derr et al., 2016) was used to quantify aligned reads using a transcript annotation file containing all RefSeq genes filtered to select only 'NM' transcripts, and extending the transcripts up to 1,000 bases past the end of the annotated 3 ' end (-wExt 1000, -task score3p), multi-mapped reads (-multimap ignore) were discarded. DEBrowser was used to analyze the most varied genes, DESeq2 was used to perform differential expression analysis(Love et al., 2014). Data were transformed using rlog within DEseq2, and prcomp was used to calculate the PCs for principal component analysis (PCA). Mouse RNA-seq data were downloaded from GSE77695, GSE109125, and GSE116092, and aligned to the mouse reference genome (mm10) using STAR (version 2.1.6) (Dobin et al., 2013). Counts of reads aligned to RefSeq genes were quantified using RSEM (version 1.3.1) (Li and Dewey, 2011) and normalized using DEseq2.

Single cell RNA-Seq processing and analysis. The Cell Ranger software package (10X Genomics) was used to perform sample demultiplexing, barcode processing, and single cell 3' gene counting. Default settings were used. The filtered gene matrices 
generated by Cell Ranger were used as input into the open-source R package Seurat 3.0 (http://satijalab.org/seurat/) (Stuart et al., 2019). FindNeighbors and FindClusters (using the default resolution of 0.6) were then run on the PCA reduction. FindMarkers was used to identify differentially expressed genes among clusters. Pseudotime analysis was done using monocle (version 2) (Qiu et al., 2017b). Cluster information (for color coding the cells for display) was imported from the Seurat analysis. The raw count data from the Seurat object was read into monocle and the standard workflow was followed: estimateSizeFactors, estimateDispersions, and detectGenes(min_expr=1) were called. Then, the dispersion table was calculated and subsetted to generate ordering genes with mean_expression $>=0.1$ and dispersion_empirical $>=$ dispersion_fit. The data was reduced to two dimensions and the cells were ordered (using the orderCells function). plot_cell_trajectory was used to create pseudotime trajectories and plot_genes_in_pseudotime (with its default settings, which rescales expression to relative values) used to show individual gene expression as a function of pseudotime.

ATAC-Seq analysis. Paired-end reads were filtered with trimmomatic (version 0.32) (Bolger et al., 2014), aligned with Bowtie2 (version 2.2.3) (Langmead and Salzberg, 2012) to a reference genome hg19. The duplicates were removed using Picard's MarkDuplicates (version 0.32). To be able to accurately call the peaks, each aligned read was first trimmed to the 9-bases at the 5' end, the region where the Tn5 transposase cuts the DNA. To smooth the peaks, the start site of the trimmed reads were extended up and down stream for 10 bases. Peaks were called using these adjusted aligned reads with MACS2 (Zhang et al., 2008). The adjusted aligned reads were converted to tdf files using IGVTools (IGVtools count -w5) (version 2.3.31) (Robinson et al., 2011) for visualization. The Tn5 transposase accessible region was used as input for JASPAR motif analysis (http://jaspar.genereg.net/). Mouse ATAC-Seq data was downloaded from GSE77695, GSE100738, and GSE116091, and was analyzed as above using mm10 as the reference genome.

Cas12a RNP-mediated knockout in NK cells. NK cells from PBMCs were isolated with EasySep $^{\text {TM }}$ Human NK Cell Isolation Kit (STEMCELL, 17955), and after culture in NK 
MACS Medium (MACS,130-114-429) for 7 days, the NK cells were ready for electroporation. Two Cas12a target sites (PAM underlined) within RUNX3 sequences were chosen for editing: 5'-TTTCACCCTGACCATCACTGTGTTCAC-3' and 5'CTTACCTCGCCCACTGCGGCCCACGAA-3'. The following Cas12a target site in adenoassociated virus integration site 1 (AAVS1) was used as a control chromosomal DNA target: 5'-TTTATCTGTCCCCTCCACCCCACAGTG-3'. Chemically end-protected (Alt-R) AsCas12a crRNAs were synthesized for each target site by IDT. Enhanced AsCas12a (enAsCas12a) (Kleinstiver et al., 2019) coding sequence was engineered to include three nuclear localization signal sequences and cloned into a pet21a expression vector for expression in, and purification from E. coli, as previously described (Liu et al., 2019). For each electroporation, 200 pmol crRNA and 100 pmol recombinant enAsCas12a protein were mixed at room temperature for $20 \mathrm{~min}$. 1 million NK cells were resuspended in $20 \mathrm{ul}$ 4D nucleofector master mix (82\% P3 + 18\% supplement 1; Lonza, V4XP-3032) and then mixed with Cas12a RNPs for electroporation using program CM137 (Rautela et al., 2020). The electroporated NK cells were ready for downstream experiments after culture in MACS medium for 5 days.

In vivo treatment of IL-2. NOD-Prkdc scid/L2rg ${ }^{t m 1 W_{j l}}$ (NSG) mice were purchased from The Jackson Laboratory (Bar Harbor, ME) and engrafted with human CD34+ ${ }^{+}$hematopoietic stem cells derived from umbilical cord blood (UCB). UCB was obtained from donors that were consented under an approved IRB protocol at the UMass Memorial Medical Center, Department of General Obstetrics and Gynecology (Worcester, MA), and all samples used for engraftment were de-identified. UCB was processed as previously described and underwent CD3 T cell depletion(Brehm et al., 2010). For engraftment, NSG mice between 3 to 4 weeks of age received $100 \mathrm{cGy}$ irradiation and were then injected IV with 100,000 CD34+ cells (Hasgur et al., 2016). Human immune system development was evaluated by flow cytometry at 16 weeks post-HSC injection.

The double-stranded (ds) adeno-associated virus (AAV) vectors were engineered and packaged as previously described (He et al., 2013). Briefly, full-length cDNA encoding human IL-2 were subcloned into a dsAAV plasmid (McCarty et al., 2001) 
containing the murine preproinsulin II promoter. dsAAV vector packaging with serotype 8 capsid protein was produced by the Viral Vector Core at the University of Massachusetts Medical School Horae Gene Therapy Center (Worcester, MA, USA). HSC-engrafted NSG mice were intraperitoneally injected with $2.5 \times 10^{11}$ particles of the purified AAV8-hulL-2 (AAV-IL-2). 6 weeks later, the blood, spleen, and liver were harvested for detection of CD56 or IFN-Y production from NK cells.

\section{Statistics}

Statistical test was performed using GraphPad Prism. The usage of paired or unpaired two-tailed student's $t$-test was indicated in the figure legends. $p<0.05$ was considered as significant. Variance was estimated by calculating the mean \pm s.e.m. in each group. Variances among groups of samples were compared using the F-test function in GraphPad.

\section{Data and code availability}

The data that support the findings of this study are available within the manuscript and in its supplementary information files. Bulk and single-cell RNA-Seq, and ATAC-Seq datasets generated by this study, can be found at: NCBI Gene Expression Omnibus (GEO): GSE168212. Areg expression and ATAC-Seq data generated by previous studies are available from NCBI GEO:GSE77695, GSE109125, and GSE11609 (Pokrovskii et al., 2019; Shih et al., 2016; Yoshida et al., 2019). 


\section{REFERENCES}

Artis, D., and Spits, H. (2015). The biology of innate lymphoid cells. Nature 517, 293-301.

Ayres, J.S. (2020). The Biology of Physiological Health. Cell 181, 250-269.

Bal, S.M., Golebski, K., and Spits, H. (2020). Plasticity of innate lymphoid cell subsets. Nat. Rev. Immunol. 20, 552-565.

Barrow, A.D., and Colonna, M. (2019). Innate lymphoid cell sensing of tissue vitality. Curr. Opin. Immunol. 56, 82-93.

Barton, K., Muthusamy, N., Fischer, C., Ting, C.N., Walunas, T.L., Lanier, L.L., and Leiden, J.M. (1998). The Ets-1 transcription factor is required for the development of natural killer cells in mice. Immunity 9, 555-563.

Besnard, E., Hakre, S., Kampmann, M., Lim, H.W., Hosmane, N.N., Martin, A., Bassik, M.C., Verschueren, E., Battivelli, E., Chan, J., et al. (2016). The mTOR Complex Controls HIV Latency. Cell Host Microbe 20, 785-797.

Björkström, N.K., Ljunggren, H.-G., and Sandberg, J.K. (2010). CD56 negative NK cells: origin, function, and role in chronic viral disease. Trends Immunol. 31, 401-406.

Bolger, A.M., Lohse, M., and Usadel, B. (2014). Trimmomatic: a flexible trimmer for Illumina sequence data. Bioinformatics 30, 2114-2120.

Brehm, M.A., Cuthbert, A., Yang, C., Miller, D.M., Dilorio, P., Laning, J., Burzenski, L., Gott, B., Foreman, O., Kavirayani, A., et al. (2010). Parameters for establishing humanized mouse models to study human immunity: analysis of human hematopoietic stem cell engraftment in three immunodeficient strains of mice bearing the IL2rgamma(null) mutation. Clin. Immunol. 135, 84-98.

Chen, L., Youssef, Y., Robinson, C., Ernst, G.F., Carson, M.Y., Young, K.A., Scoville, S.D., Zhang, X., Harris, R., Sekhri, P., et al. (2018). CD56 Expression Marks Human Group 2 Innate Lymphoid Cell Divergence from a Shared NK Cell and Group 3 Innate Lymphoid Cell Developmental Pathway. Immunity 49, 464-476.e4.

Cherrier, D.E., Serafini, N., and Di Santo, J.P. (2018). Innate Lymphoid Cell Development: A T Cell Perspective. Immunity 48, 1091-1103.

Colonna, M. (2018). Innate Lymphoid Cells: Diversity, Plasticity, and Unique Functions in Immunity. Immunity 48, 1104-1117.

Cortez, V.S., Cervantes-Barragan, L., Robinette, M.L., Bando, J.K., Wang, Y., Geiger, T.L., Gilfillan, S., Fuchs, A., Vivier, E., Sun, J.C., et al. (2016). Transforming Growth Factor- $\beta$ Signaling Guides the Differentiation of Innate Lymphoid Cells in Salivary Glands. Immunity 44, 1127-1139. 
Cortez, V.S., Ulland, T.K., Cervantes-Barragan, L., Bando, J.K., Robinette, M.L., Wang, Q., White, A.J., Gilfillan, S., Cella, M., and Colonna, M. (2017). SMAD4 impedes the conversion of NK cells into ILC1-like cells by curtailing non-canonical TGF- $\beta$ signaling. Nature Immunology 18, 995-1003.

Crinier, A., Milpied, P., Escalière, B., Piperoglou, C., Galluso, J., Balsamo, A., Spinelli, L., Cervera-Marzal, I., Ebbo, M., Girard-Madoux, M., et al. (2018). High-Dimensional SingleCell Analysis Identifies Organ-Specific Signatures and Conserved NK Cell Subsets in Humans and Mice. Immunity 49, 971-986.e5.

Crowell, T.A., Gebo, K.A., Blankson, J.N., Korthuis, P.T., Yehia, B.R., Rutstein, R.M., Moore, R.D., Sharp, V., Nijhawan, A.E., Mathews, W.C., et al. (2015). Hospitalization Rates and Reasons Among HIV Elite Controllers and Persons With Medically Controlled HIV Infection. J. Infect. Dis. 211, 1692-1702.

Das, L., and Levine, A.D. (2008). TGF- $\beta$ inhibits IL-2 production and promotes cell cycle arrest in TCR-activated effector/memory T cells in the presence of sustained TCR signal transduction. J. Immunol 180, 1490-1498.

Deeks, S.G., Tracy, R., and Douek, D.C. (2013). Systemic effects of inflammation on health during chronic HIV infection. Immunity 39, 633-645.

Derr, A., Yang, C., Zilionis, R., Sergushichev, A., Blodgett, D.M., Redick, S., Bortell, R., Luban, J., Harlan, D.M., Kadener, S., et al. (2016). End Sequence Analysis Toolkit (ESAT) expands the extractable information from single-cell RNA-seq data. Genome Res. 26, 1397-1410.

Dobin, A., Davis, C.A., Schlesinger, F., Drenkow, J., Zaleski, C., Jha, S., Batut, P., Chaisson, M., and Gingeras, T.R. (2013). STAR: ultrafast universal RNA-seq aligner. Bioinformatics 29, 15-21.

Donia, M., McCubrey, J.A., Bendtzen, K., and Nicoletti, F. (2010). Potential use of rapamycin in HIV infection. Br. J. Clin. Pharmacol. 70, 784-793.

Ebbo, M., Crinier, A., Vély, F., and Vivier, E. (2017). Innate lymphoid cells: major players in inflammatory diseases. Nat. Rev. Immunol. 17, 665-678.

Eriksson, E.M., Milush, J.M., Ho, E.L., Batista, M.D., Holditch, S.J., Keh, C.E., Norris, P.J., Keating, S.M., Deeks, S.G., Hunt, P.W., et al. (2012). Expansion of CD8+ T cells lacking Sema4D/CD100 during HIV-1 infection identifies a subset of $\mathrm{T}$ cells with decreased functional capacity. Blood 119, 745-755.

Ganeshan, K., and Chawla, A. (2014). Metabolic regulation of immune responses. Annu. Rev. Immunol. 32, 609-634.

Gibbons, H.R., Shaginurova, G., Kim, L.C., Chapman, N., Spurlock, C.F., 3rd, and Aune, T.M. (2018). Divergent IncRNA GATA3-AS1 Regulates GATA3 Transcription in T-Helper 2 Cells. Front. Immunol. 9, 2512. 
Hasgur, S., Aryee, K.E., Shultz, L.D., Greiner, D.L., and Brehm, M.A. (2016). Generation of Immunodeficient Mice Bearing Human Immune Systems by the Engraftment of Hematopoietic Stem Cells. Methods Mol. Biol. 1438, 67-78.

Hashimshony, T., Senderovich, N., Avital, G., Klochendler, A., de Leeuw, Y., Anavy, L., Gennert, D., Li, S., Livak, K.J., Rozenblatt-Rosen, O., et al. (2016). CEL-Seq2: sensitive highly-multiplexed single-cell RNA-Seq. Genome Biol. 17, 77.

Hazenberg, M.D., and Spits, H. (2014). Human innate lymphoid cells. Blood 124, 700709.

He, Y., Weinberg, M.S., Hirsch, M., Johnson, M.C., Tisch, R., Samulski, R.J., and Li, C. (2013). Kinetics of adeno-associated virus serotype 2 (AAV2) and AAV8 capsid antigen presentation in vivo are identical. Hum. Gene Ther. 24, 545-553.

He, Y., Guo, Y., Fan, C., Lei, Y., Zhou, Y., Zhang, M., Ye, C., Ji, G., Ma, L., Lian, J., et al. (2017). Interferon-a-Enhanced CD100/Plexin-B1/B2 Interactions Promote Natural Killer Cell Functions in Patients with Chronic Hepatitis C Virus Infection. Front. Immunol. 8, 1435.

Heredia, A., Le, N., Gartenhaus, R.B., Sausville, E., Medina-Moreno, S., Zapata, J.C., Davis, C., Gallo, R.C., and Redfield, R.R. (2015). Targeting of mTOR catalytic site inhibits multiple steps of the HIV-1 lifecycle and suppresses HIV-1 viremia in humanized mice. Proc. Natl. Acad. Sci. U. S. A. 112, 9412-9417.

Ikushima, H., and Miyazono, K. (2010). TGF $\beta$ signalling: a complex web in cancer progression. Nat. Rev. Cancer 10, 415-424.

Ito, Y., and Miyazono, K. (2003). RUNX transcription factors as key targets of TGF-beta superfamily signaling. Curr. Opin. Genet. Dev. 13, 43-47.

Ito, K., Lim, A.C.-B., Salto-Tellez, M., Motoda, L., Osato, M., Chuang, L.S.H., Lee, C.W.L., Voon, D.C.-C., Koo, J.K.W., Wang, H., et al. (2008). RUNX3 attenuates beta-catenin/T cell factors in intestinal tumorigenesis. Cancer Cell 14, 226-237.

Jost, S., Tomezsko, P.J., Rands, K., Toth, I., Lichterfeld, M., Gandhi, R.T., and Altfeld, M. (2014). CD4+ T-cell help enhances NK cell function following therapeutic HIV-1 vaccination. J. Virol. 88, 8349-8354.

Kim, D., Pertea, G., Trapnell, C., Pimentel, H., Kelley, R., and Salzberg, S.L. (2013). TopHat2: accurate alignment of transcriptomes in the presence of insertions, deletions and gene fusions. Genome Biol. 14, R36.

Kleinstiver, B.P., Sousa, A.A., Walton, R.T., Tak, Y.E., Hsu, J.Y., Clement, K., Welch, M.M., Horng, J.E., Malagon-Lopez, J., Scarfò, I., et al. (2019). Engineered CRISPRCas12a variants with increased activities and improved targeting ranges for gene, epigenetic and base editing. Nat. Biotechnol. 37, 276-282. 
Klose, C.S.N., and Artis, D. (2016). Innate lymphoid cells as regulators of immunity, inflammation and tissue homeostasis. Nat. Immunol. 17, 765-774.

Kløverpris, H.N., Kazer, S.W., Mjösberg, J., Mabuka, J.M., Wellmann, A., Ndhlovu, Z., Yadon, M.C., Nhamoyebonde, S., Muenchhoff, M., Simoni, Y., et al. (2016). Innate Lymphoid Cells Are Depleted Irreversibly during Acute HIV-1 Infection in the Absence of Viral Suppression. Immunity 44, 391-405.

Kumanogoh, A., and Kikutani, H. (2004). Biological functions and signaling of a transmembrane semaphorin, CD100/Sema4D. Cell. Mol. Life Sci. 61, 292-300.

Langmead, B., and Salzberg, S.L. (2012). Fast gapped-read alignment with Bowtie 2. Nat. Methods 9, 357-359.

Lanier, L.L. (2009). DAP10- and DAP12-associated receptors in innate immunity. Immunol. Rev. 227, 150-160.

Li, B., and Dewey, C.N. (2011). RSEM: accurate transcript quantification from RNA-Seq data with or without a reference genome. BMC Bioinformatics 12, 323.

Li, B.W.S., Stadhouders, R., de Bruijn, M.J.W., Lukkes, M., Beerens, D.M.J.M., Brem, M.D., KleinJan, A., Bergen, I., Vroman, H., Kool, M., et al. (2017). Group 2 Innate Lymphoid Cells Exhibit a Dynamic Phenotype in Allergic Airway Inflammation. Front. Immunol. 8, 1684.

Liang, J.-R., Martinez, A., Lane, J.D., Mayor, U., Clague, M.J., and Urbé, S. (2015). USP 30 deubiquitylates mitochondrial $P$ arkin substrates and restricts apoptotic cell death. EMBO Rep. 16, 618-627.

Lim, A.I., Li, Y., Lopez-Lastra, S., Stadhouders, R., Paul, F., Casrouge, A., Serafini, N., Puel, A., Bustamante, J., Surace, L., et al. (2017). Systemic Human ILC Precursors Provide a Substrate for Tissue ILC Differentiation. Cell 168, 1086-1100.e10.

Liu, P., Luk, K., Shin, M., Idrizi, F., Kwok, S., Roscoe, B., Mintzer, E., Suresh, S., Morrison, K., Frazão, J.B., et al. (2019). Enhanced Cas12a editing in mammalian cells and zebrafish. Nucleic Acids Res. 47, 4169-4180.

Love, M., Anders, S., and Huber, W. (2014). Differential analysis of count data--the DESeq2 package. Genome Biol. 15, 550.

Lugli, E., Marcenaro, E., and Mavilio, D. (2014). NK Cell Subset Redistribution during the Course of Viral Infections. Front. Immunol. 5, 390.

Maric, J., Ravindran, A., Mazzurana, L., Van Acker, A., Rao, A., Kokkinou, E., Ekoff, M., Thomas, D., Fauland, A., Nilsson, G., et al. (2019). Cytokine-induced endogenous production of prostaglandin D2 is essential for human group 2 innate lymphoid cell activation. J. Allergy Clin. Immunol. 143, 2202-2214.e5. 
Martin, A.R., Pollack, R.A., Capoferri, A., Ambinder, R.F., Durand, C.M., and Siliciano, R.F. (2017). Rapamycin-mediated mTOR inhibition uncouples HIV-1 latency reversal from cytokine-associated toxicity. J. Clin. Invest. 127, 651-656.

Mavilio, D., Lombardo, G., Benjamin, J., Kim, D., Follman, D., Marcenaro, E., Angeline O'Shea, M., Kinter, A., Kovacs, C., Moretta, A., et al. (2005). Characterization of CD56/CD16+ natural killer (NK) cells: A highly dysfunctional NK subset expanded in HIVinfected viremic individuals. Proc. Natl. Acad. Sci. U. S. A. 102, 2886-2891.

McCarty, D.M., Monahan, P.E., and Samulski, R.J. (2001). Self-complementary recombinant adeno-associated virus (scAAV) vectors promote efficient transduction independently of DNA synthesis. Gene Ther. 8, 1248-1254.

Medzhitov, R., Schneider, D.S., and Soares, M.P. (2012). Disease tolerance as a defense strategy. Science 335, 936-941.

Mizrahi, S. 'ar, Markel, G., Porgador, A., Bushkin, Y., and Mandelboim, O. (2007). CD100 on NK Cells Enhance IFNy Secretion and Killing of Target Cells Expressing CD72. PLoS One 2, e818.

Monticelli, L.A., Sonnenberg, G.F., Abt, M.C., Alenghat, T., Ziegler, C.G.K., Doering, T.A., Angelosanto, J.M., Laidlaw, B.J., Yang, C.Y., Sathaliyawala, T., et al. (2011). Innate lymphoid cells promote lung-tissue homeostasis after infection with influenza virus. Nat. Immunol. 12, 1045-1054.

Monticelli, L.A., Osborne, L.C., Noti, M., Tran, S.V., Zaiss, D.M.W., and Artis, D. (2015). IL-33 promotes an innate immune pathway of intestinal tissue protection dependent on amphiregulin-EGFR interactions. Proc. Natl. Acad. Sci. U. S. A. 112, 10762-10767.

Pokrovskii, M., Hall, J.A., Ochayon, D.E., Yi, R., Chaimowitz, N.S., Seelamneni, H., Carriero, N., Watters, A., Waggoner, S.N., Littman, D.R., et al. (2019). Characterization of Transcriptional Regulatory Networks that Promote and Restrict Identities and Functions of Intestinal Innate Lymphoid Cells. Immunity 51, 185-197.e6.

Poli, A., Michel, T., Thérésine, M., Andrès, E., Hentges, F., and Zimmer, J. (2009). CD56brightnatural killer (NK) cells: an important NK cell subset. Immunology 126, 458465.

Poznanski, S.M., and Ashkar, A.A. (2019). What Defines NK Cell Functional Fate: Phenotype or Metabolism? Front. Immunol. 10, 1414.

Qiu, X., Hill, A., Packer, J., Lin, D., Ma, Y.-A., and Trapnell, C. (2017a). Single-cell mRNA quantification and differential analysis with Census. Nat. Methods 14, 309-315.

Qiu, X., Mao, Q., Tang, Y., Wang, L., Chawla, R., Pliner, H.A., and Trapnell, C. (2017b). Reversed graph embedding resolves complex single-cell trajectories. Nat. Methods 14, 979-982. 
Rautela, J., Surgenor, E., and Huntington, N.D. (2020). Drug target validation in primary human natural killer cells using CRISPR RNP. Journal of Leukocyte Biology 108, 13971408.

Ray, J.P., Staron, M.M., Shyer, J.A., Ho, P.-C., Marshall, H.D., Gray, S.M., Laidlaw, B.J., Araki, K., Ahmed, R., Kaech, S.M., et al. (2015). The Interleukin-2-mTORc1 Kinase Axis Defines the Signaling, Differentiation, and Metabolism of T Helper 1 and Follicular B Helper T Cells. Immunity 43, 690-702.

Robinson, J.T., Thorvaldsdóttir, H., Winckler, W., Guttman, M., Lander, E.S., Getz, G., and Mesirov, J.P. (2011). Integrative genomics viewer. Nat. Biotechnol. 29, 24-26.

Shan, Q., Zeng, Z., Xing, S., Li, F., Hartwig, S.M., Gullicksrud, J.A., Kurup, S.P., Van Braeckel-Budimir, N., Su, Y., Martin, M.D., et al. (2017). The transcription factor Runx3 guards cytotoxic CD8+ effector $\mathrm{T}$ cells against deviation towards follicular helper $\mathrm{T}$ cell lineage. Nat. Immunol. 18, 931-939.

Shaulian, E., and Karin, M. (2001). AP-1 in cell proliferation and survival. Oncogene 20, 2390.

Shih, H.-Y., Sciumè, G., Mikami, Y., Guo, L., Sun, H.-W., Brooks, S.R., Urban, J.F., Jr, Davis, F.P., Kanno, Y., and O'Shea, J.J. (2016). Developmental Acquisition of Regulomes Underlies Innate Lymphoid Cell Functionality. Cell 165, 1120-1133.

Spits, H., Bernink, J.H., and Lanier, L. (2016). NK cells and type 1 innate lymphoid cells: partners in host defense. Nat. Immunol. 17, 758-764.

Stuart, T., Butler, A., Hoffman, P., Hafemeister, C., Papalexi, E., Mauck, W.M., 3rd, Hao, Y., Stoeckius, M., Smibert, P., and Satija, R. (2019). Comprehensive Integration of SingleCell Data. Cell 177, 1888-1902.e21.

Theron, A.J., Anderson, R., Rossouw, T.M., and Steel, H.C. (2017). The Role of Transforming Growth Factor Beta-1 in the Progression of HIVIAIDS and Development of Non-AIDS-Defining Fibrotic Disorders. Front. Immunol. 8, 1461.

Trapnell, C., Cacchiarelli, D., Grimsby, J., Pokharel, P., Li, S., Morse, M., Lennon, N.J., Livak, K.J., Mikkelsen, T.S., and Rinn, J.L. (2014). The dynamics and regulators of cell fate decisions are revealed by pseudotemporal ordering of single cells. Nat. Biotechnol. 32, 381-386.

Turnbull, I.R., and Colonna, M. (2007). Activating and inhibitory functions of DAP12. Nat. Rev. Immunol. 7, 155-161.

Vivier, E., Artis, D., Colonna, M., Diefenbach, A., Di Santo, J.P., Eberl, G., Koyasu, S., Locksley, R.M., McKenzie, A.N.J., Mebius, R.E., et al. (2018). Innate Lymphoid Cells: 10 Years On. Cell 174, 1054-1066.

Walker, J.A., Barlow, J.L., and McKenzie, A.N.J. (2013). Innate lymphoid cells — how did 
we miss them? Nature Reviews Immunology 13, 75-87.

Wang, Y., Lifshitz, L., Gellatly, K., Vinton, C.L., Busman-Sahay, K., McCauley, S., Vangala, P., Kim, K., Derr, A., Jaiswal, S., et al. (2020). HIV-1-induced cytokines deplete homeostatic innate lymphoid cells and expand TCF7-dependent memory NK cells. Nat. Immunol. 21, 274-286.

Wiercińska-Drapalo, A., Flisiak, R., Jaroszewicz, J., and Prokopowicz, D. (2004). Increased Plasma Transforming Growth Factor- $\beta 1$ Is Associated with Disease Progression in HIV-1-Infected Patients. Viral Immunology 17, 109-113.

Wu, Y., Tian, Z., and Wei, H. (2017). Developmental and Functional Control of Natural Killer Cells by Cytokines. Front. Immunol. 8, 930.

Wu, Z., Frascaroli, G., Bayer, C., Schmal, T., and Mertens, T. (2015). Interleukin-2 from Adaptive T Cells Enhances Natural Killer Cell Activity against Human CytomegalovirusInfected Macrophages. J. Virol. 89, 6435-6441.

Yoshida, H., Lareau, C.A., Ramirez, R.N., Rose, S.A., Maier, B., Wroblewska, A., Desland, F., Chudnovskiy, A., Mortha, A., Dominguez, C., et al. (2019). The cisRegulatory Atlas of the Mouse Immune System. Cell 176, 897-912.e20.

Yudanin, N.A., Schmitz, F., Flamar, A.-L., Thome, J.J.C., Tait Wojno, E., Moeller, J.B., Schirmer, M., Latorre, I.J., Xavier, R.J., Farber, D.L., et al. (2019). Spatial and Temporal Mapping of Human Innate Lymphoid Cells Reveals Elements of Tissue Specificity. Immunity 50, 505-519.e4.

Zaiss, D.M.W., Gause, W.C., Osborne, L.C., and Artis, D. (2015). Emerging functions of amphiregulin in orchestrating immunity, inflammation, and tissue repair. Immunity 42, 216-226.

Zhang, Y., Liu, T., Meyer, C.A., Eeckhoute, J., Johnson, D.S., Bernstein, B.E., Nusbaum, C., Myers, R.M., Brown, M., Li, W., et al. (2008). Model-based analysis of ChIP-Seq (MACS). Genome Biol. 9, R137.

Zheng, Y., Collins, S.L., Lutz, M.A., Allen, A.N., Kole, T.P., Zarek, P.E., and Powell, J.D. (2007). A role for mammalian target of rapamycin in regulating $T$ cell activation versus anergy. J. Immunol. 178, 2163-2170.

Zook, E.C., Ramirez, K., Guo, X., van der Voort, G., Sigvardsson, M., Svensson, E.C., Fu, Y.-X., and Kee, B.L. (2016). The ETS1 transcription factor is required for the development and cytokine-induced expansion of ILC2. J. Exp. Med. 213, 687-696. 
A
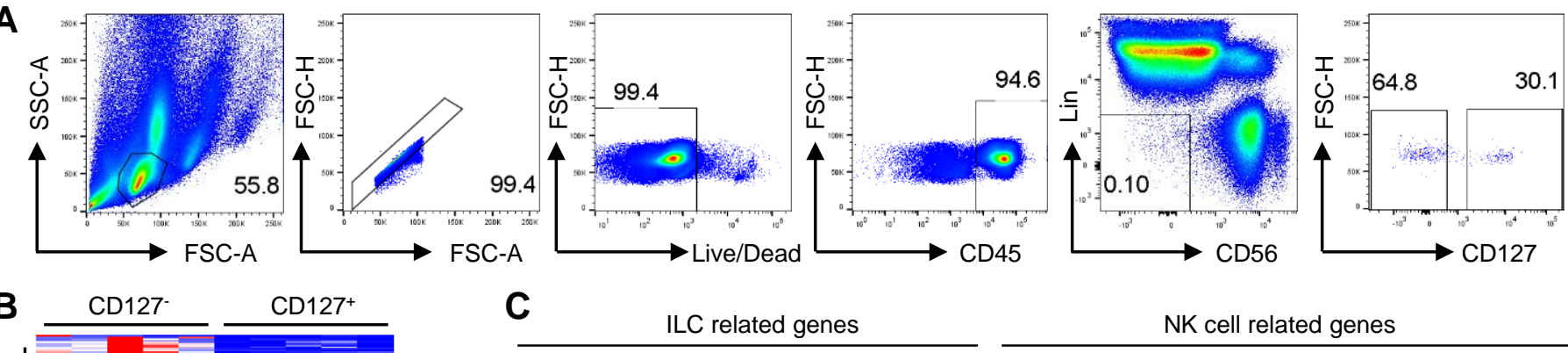

C

CD45

ILC related genes

NK cell related genes
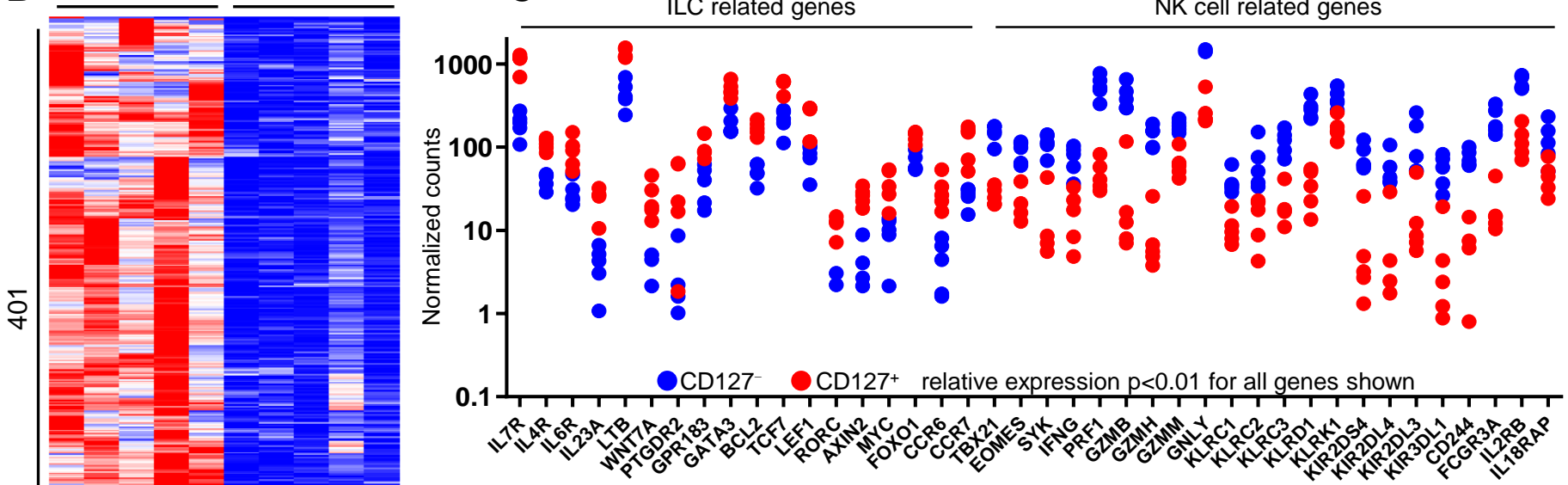

ঠ்
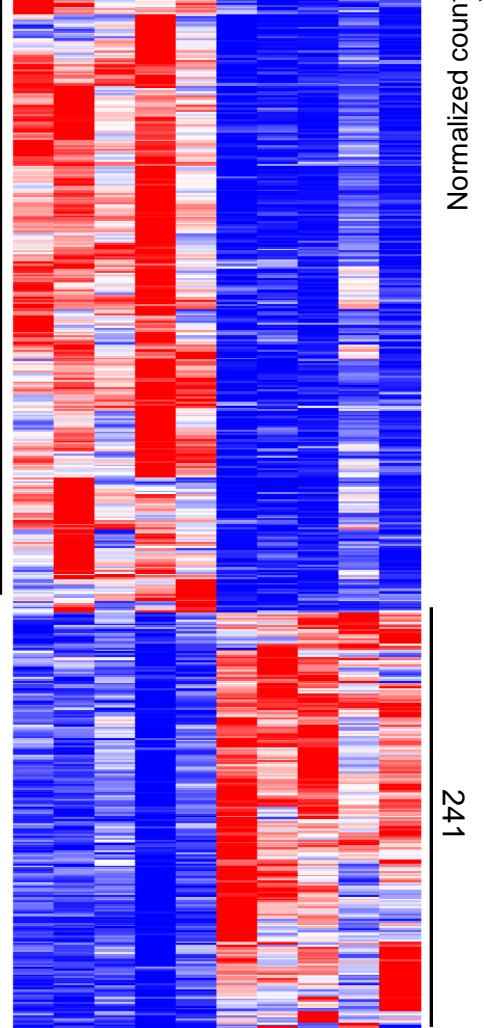

D

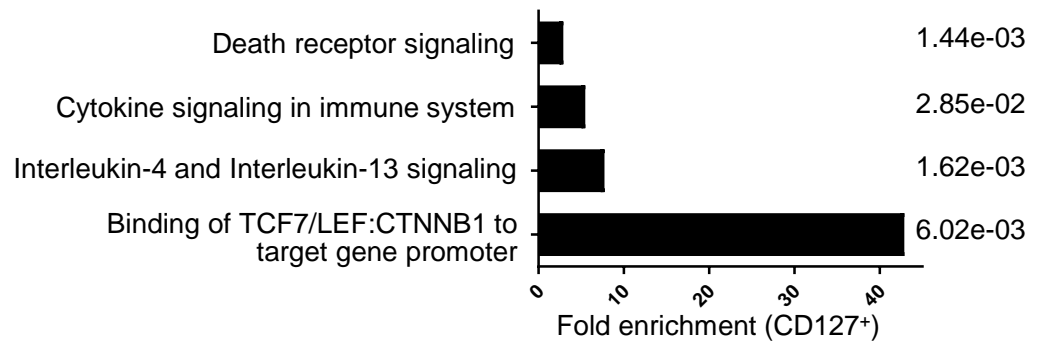

E

Platelet degranulation Immunoregulatory interactions between a lymphoid and a non-lymphoid cell DAP12 interactions

DAP12 signaling

Sema4D in semaphorin signaling Sema4D induced cell migration and growth-cone collapse
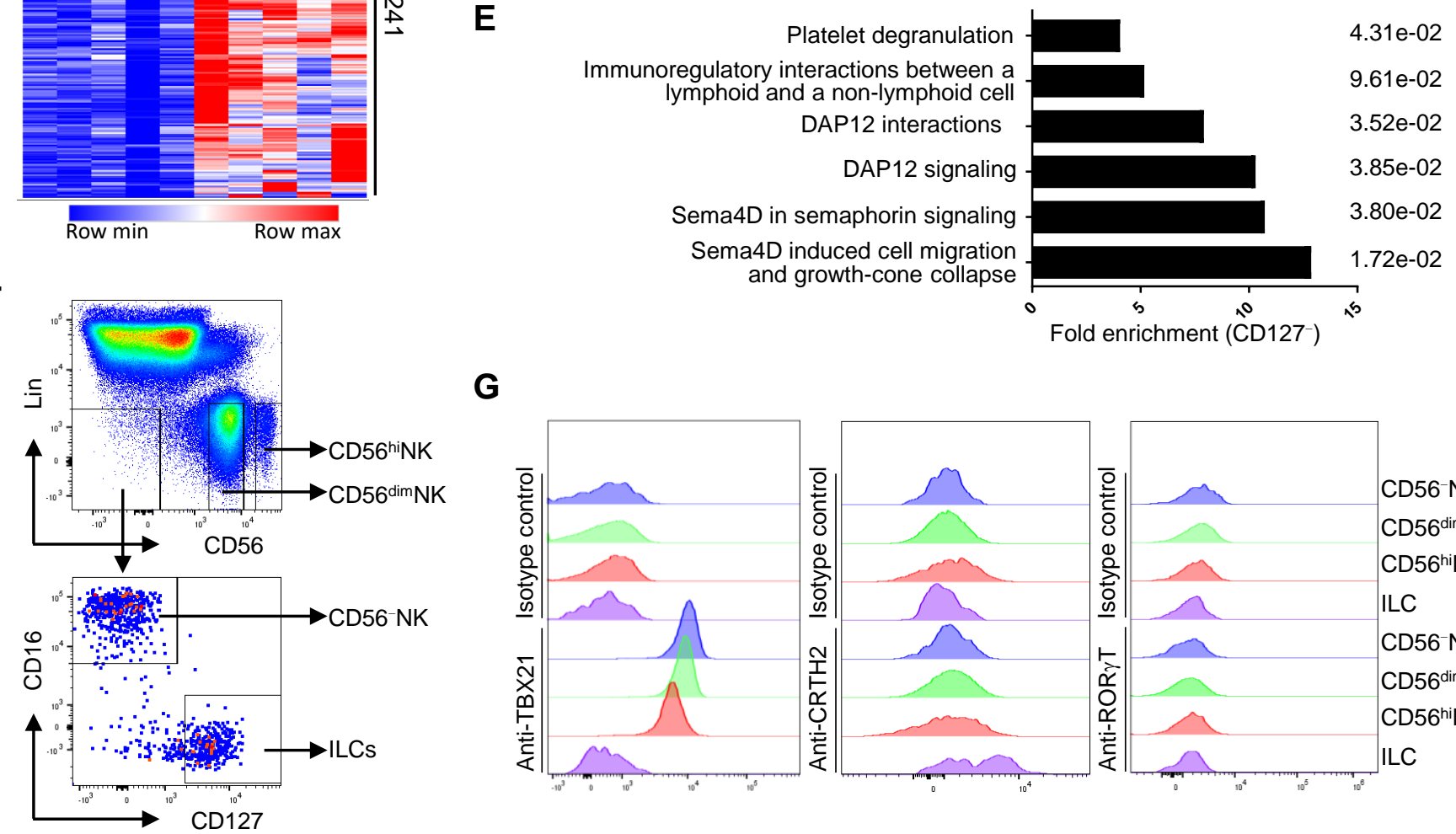

G

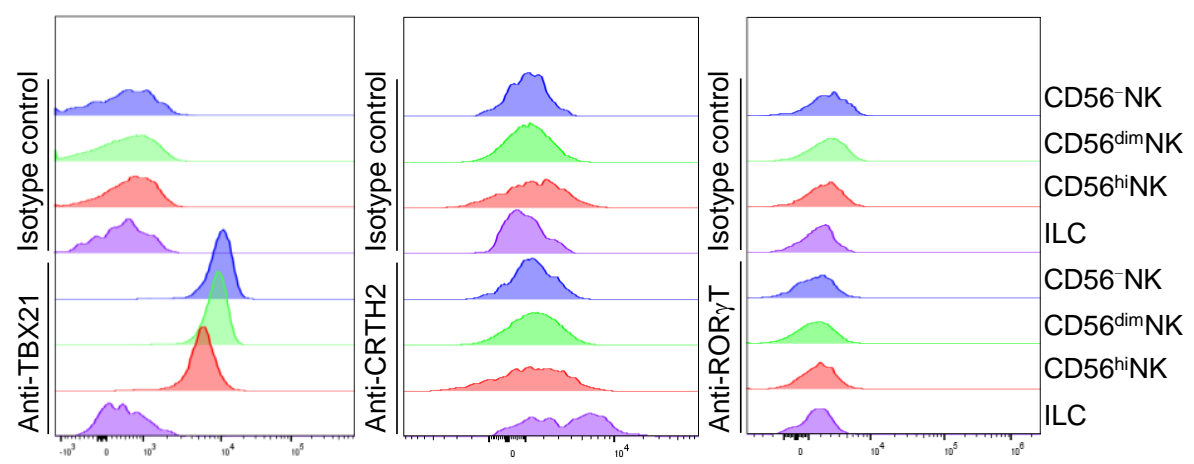



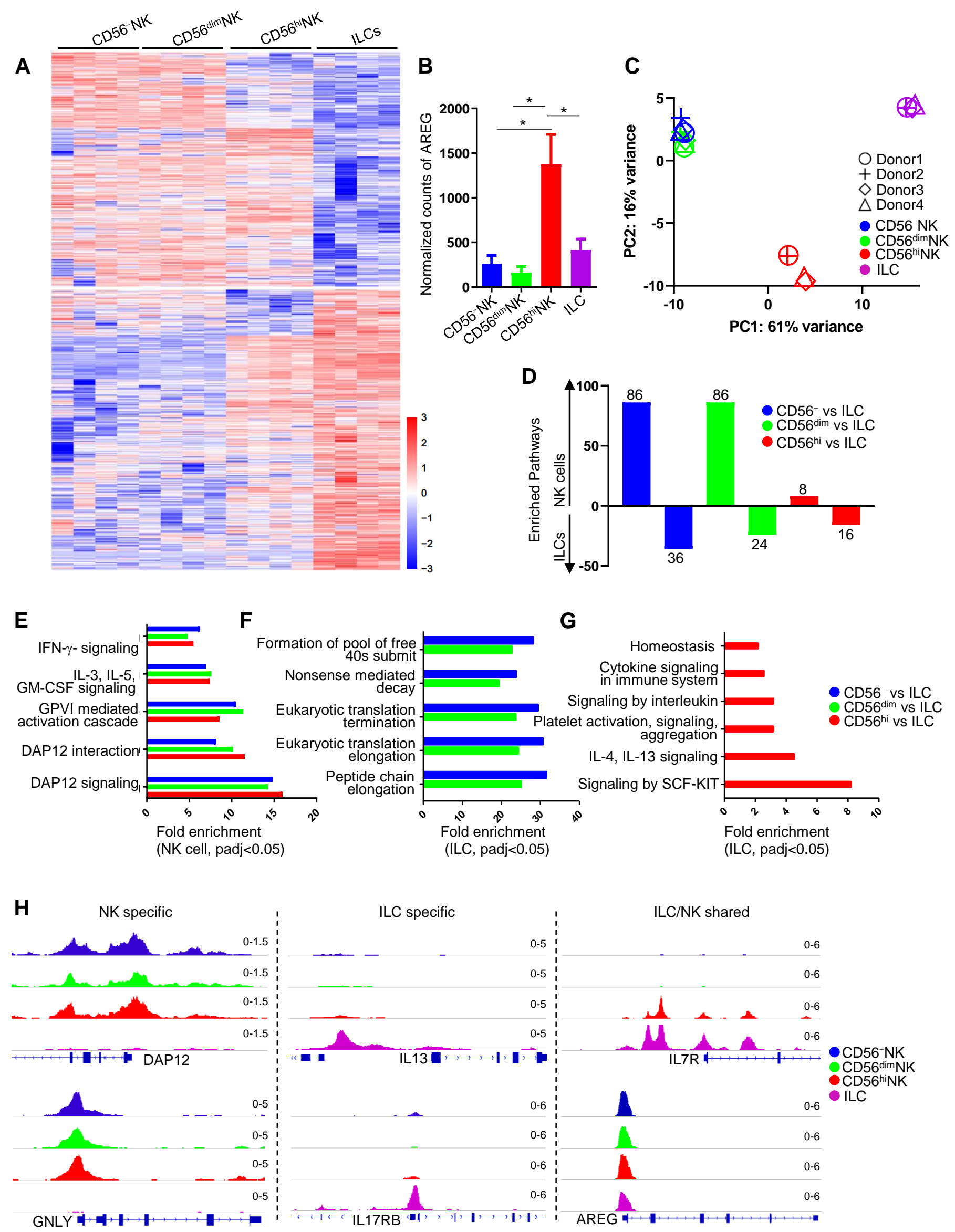

Wang et al, Figure 2 


\section{A}

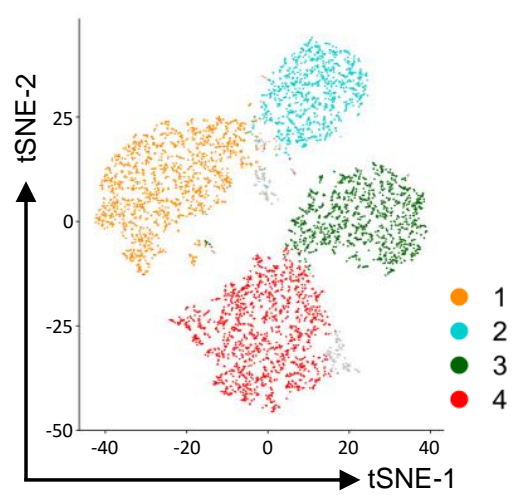

C

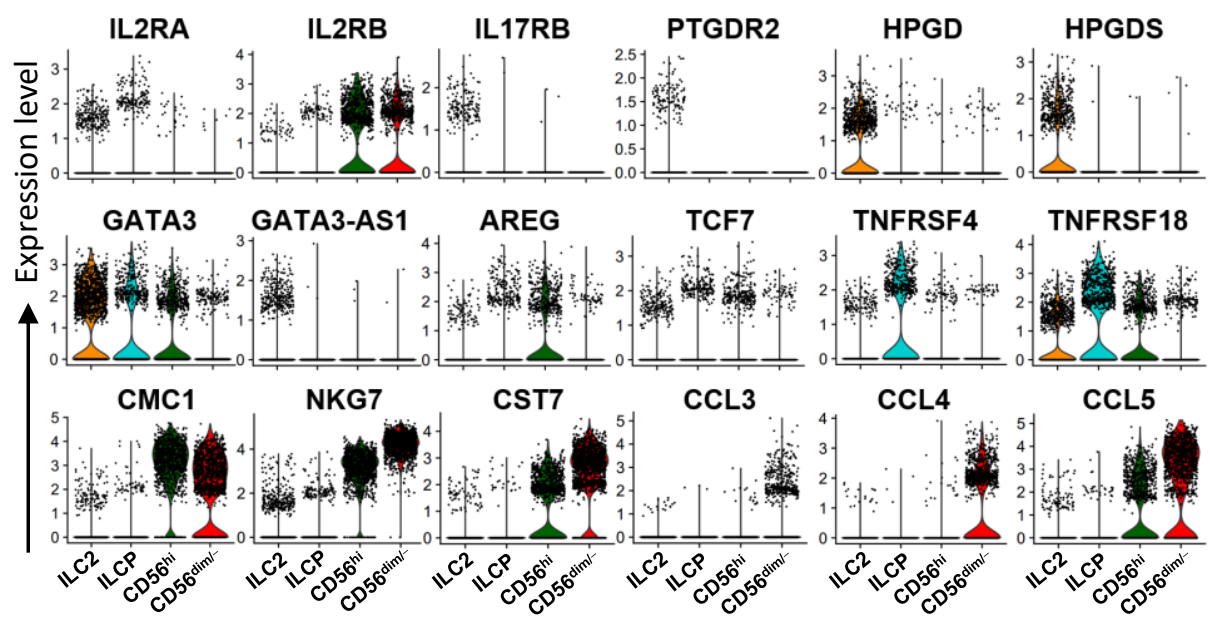

D

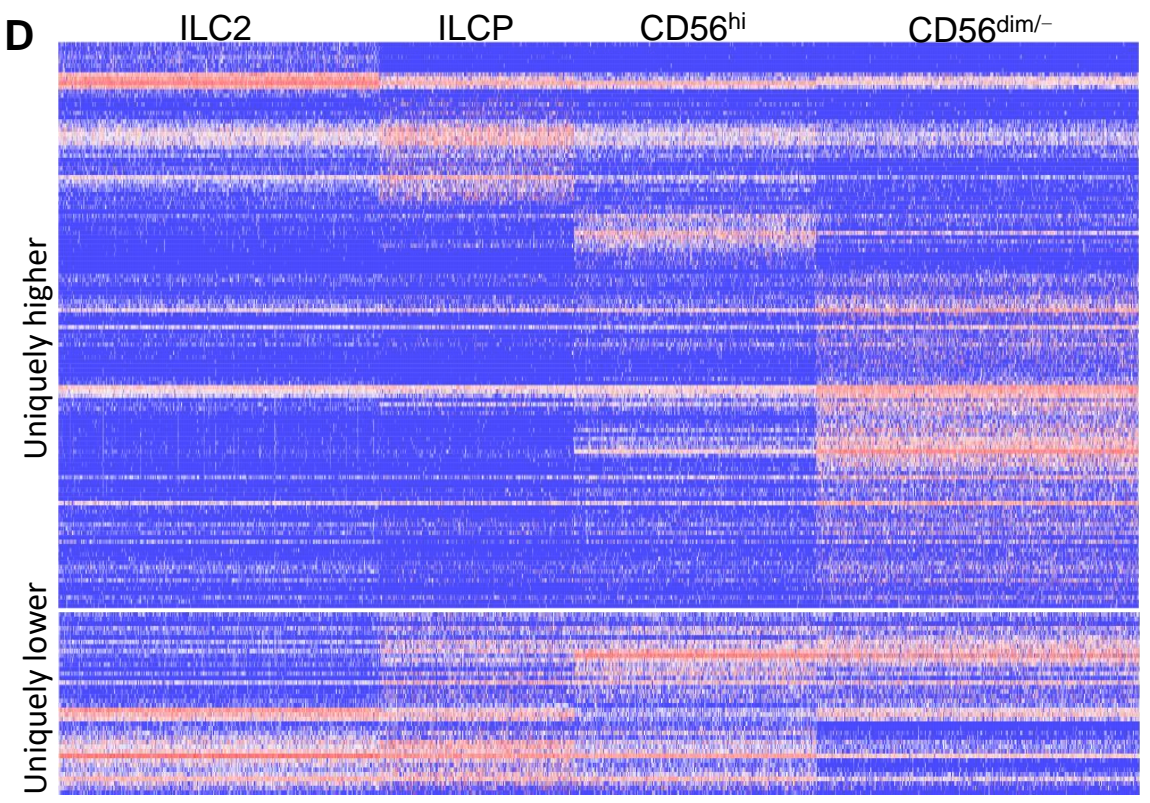

Cluster

ILC2

ILCP

CD56 hinK

CD56 dim/-NK
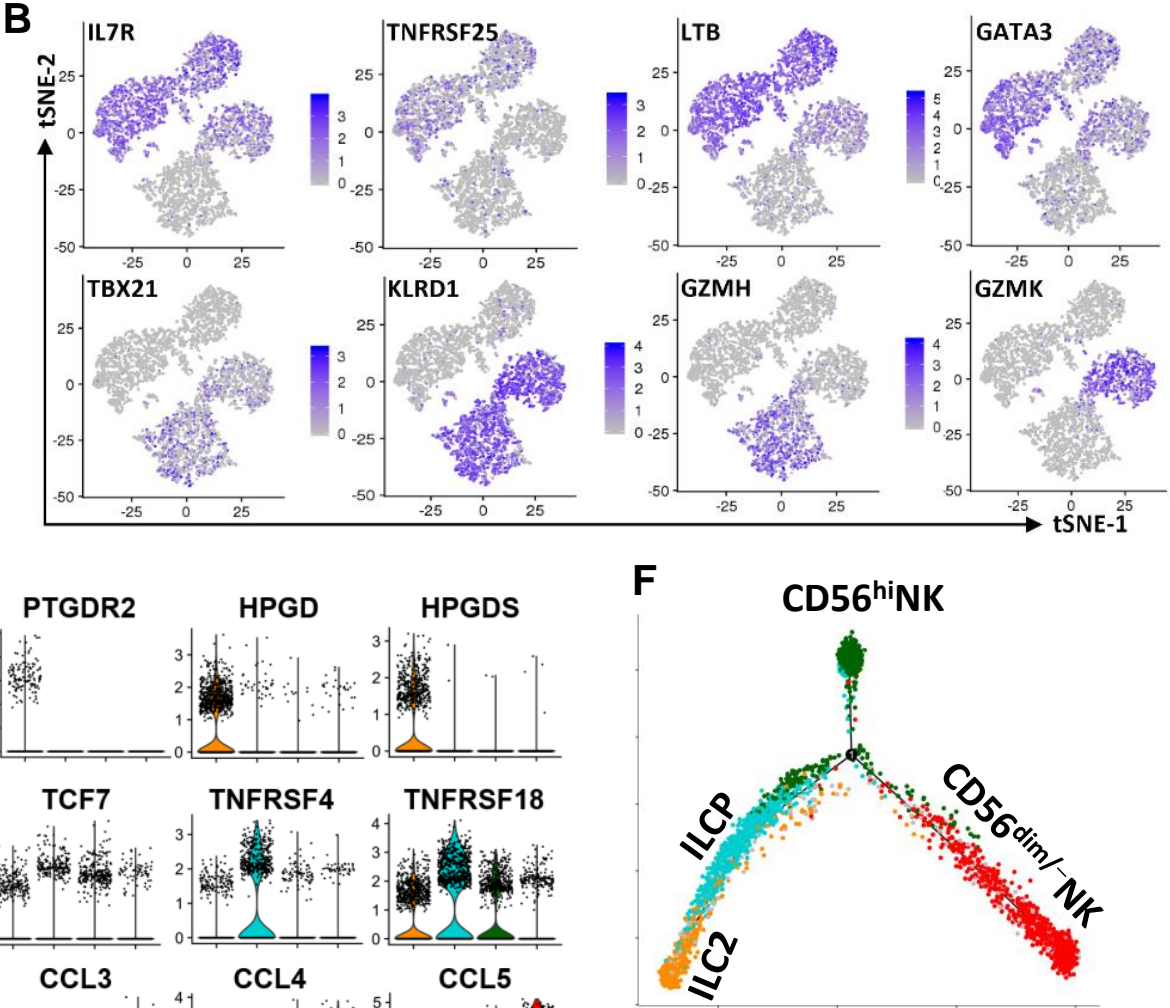

G

ETS1
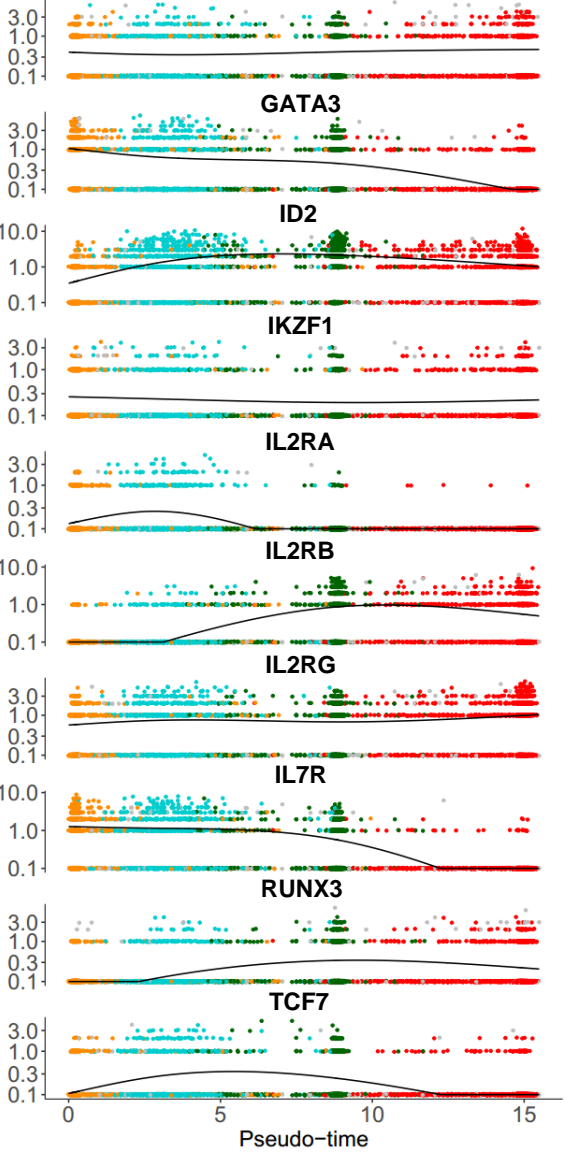

Wang et al, Figure 3 

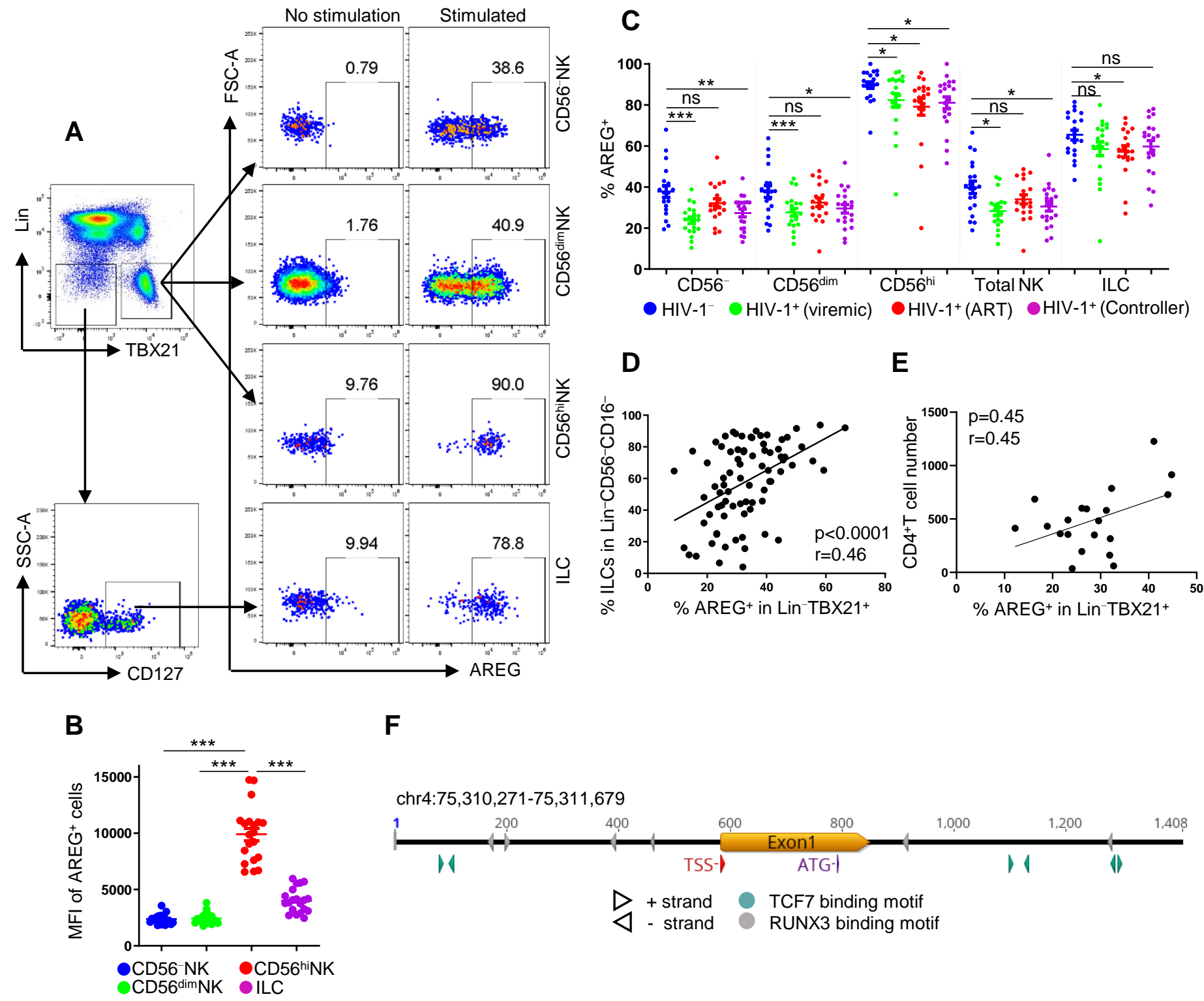

F
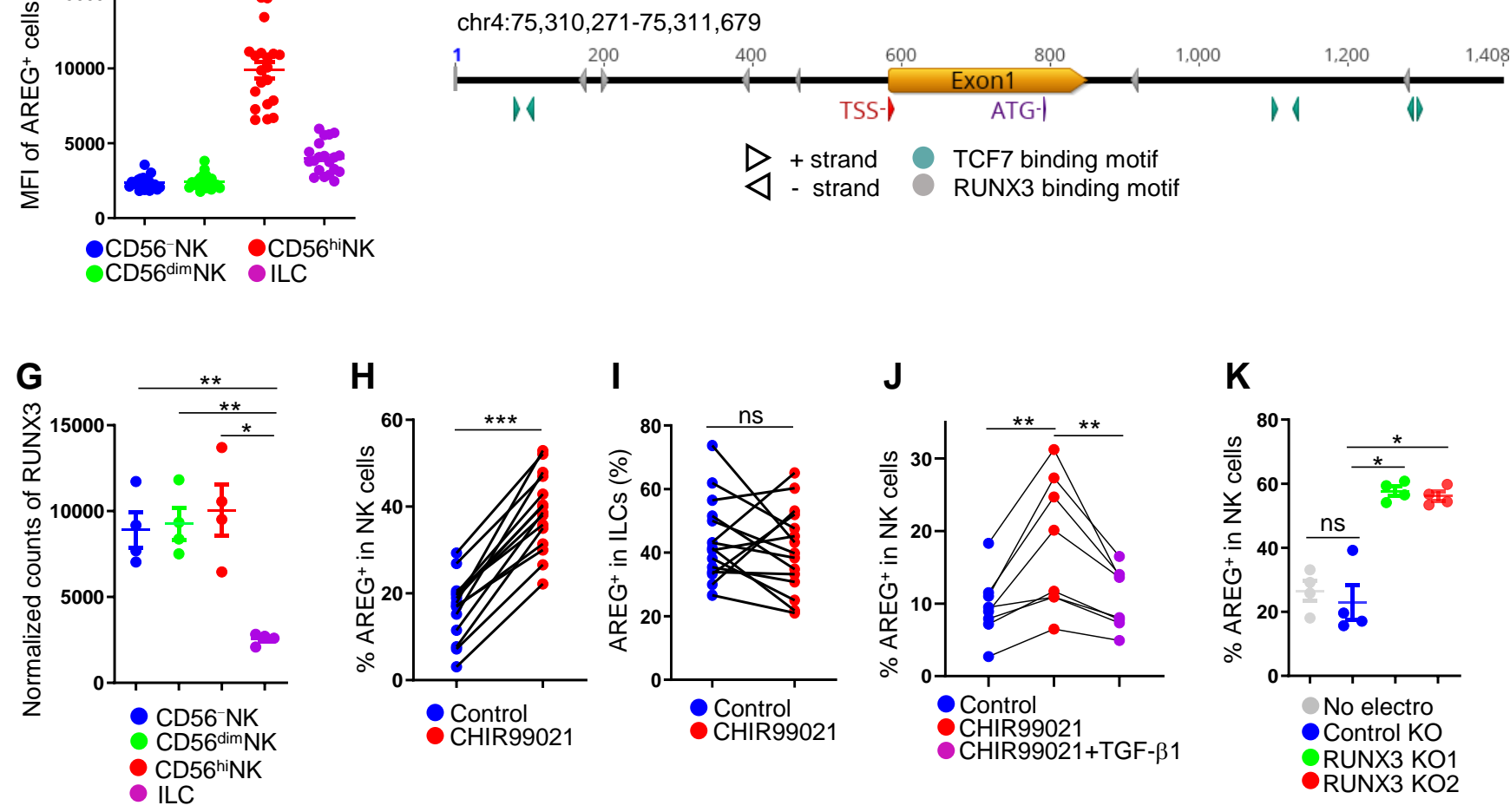

Wang et al, Figure 4 


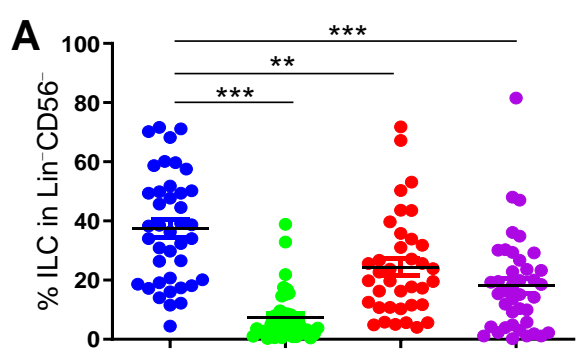

B
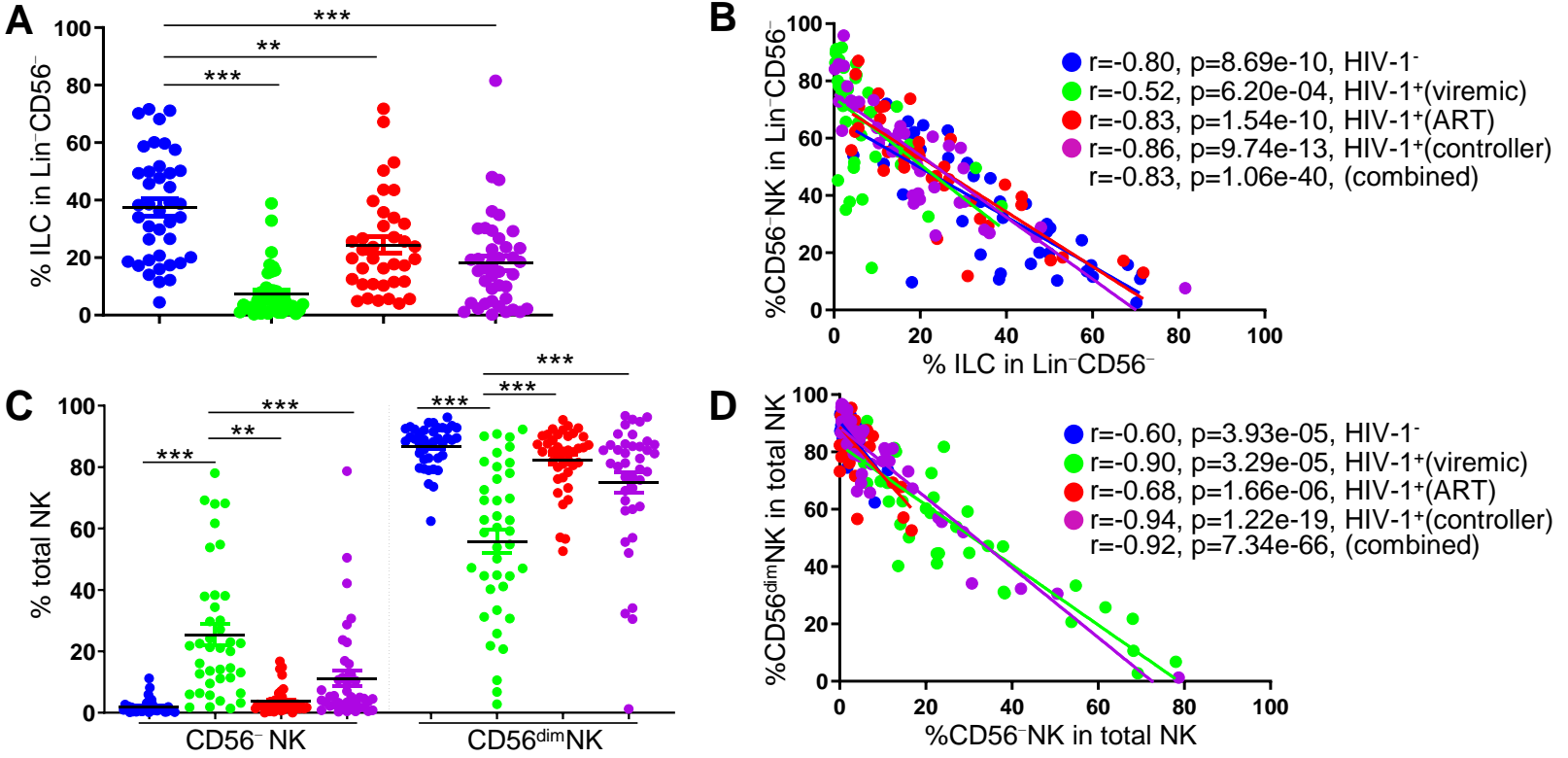

D
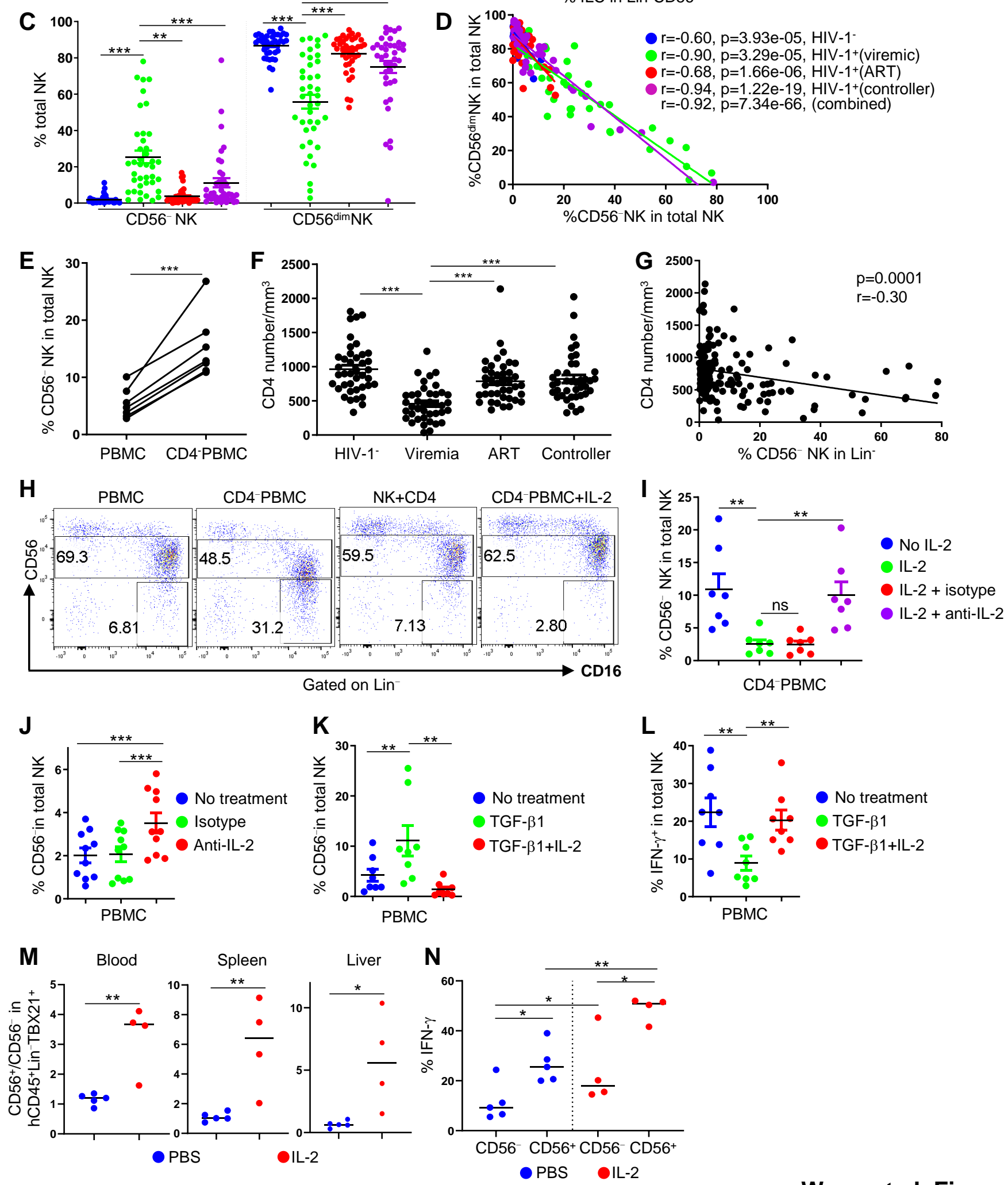

Wang et al, Figure 5 
A

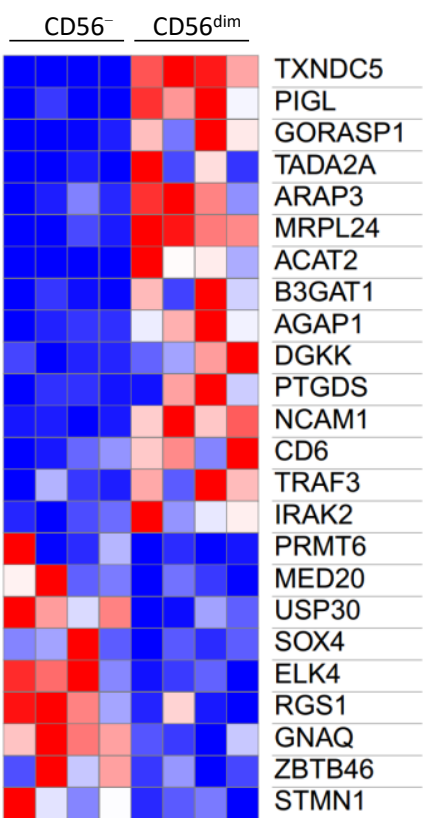

No stimulation

Row min Row max

B

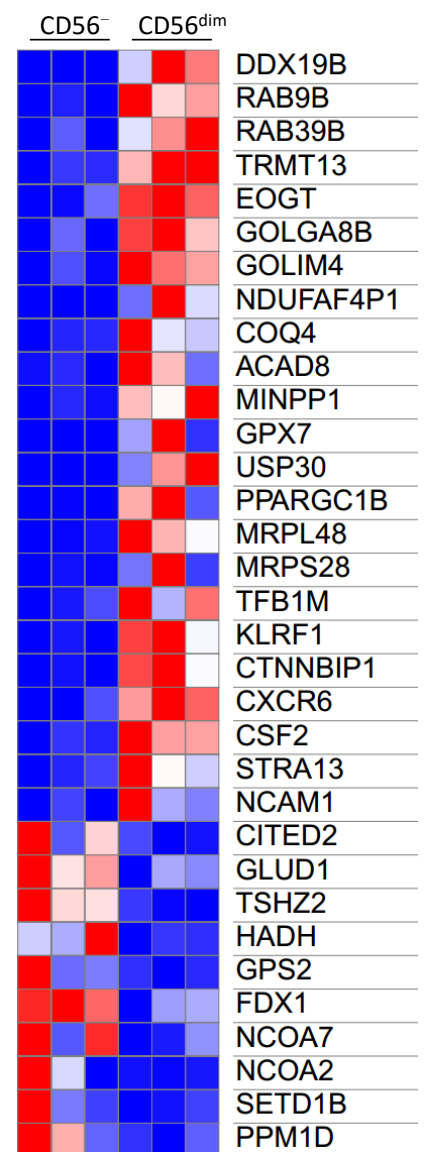

IL-12+IL-15+IL-18
C
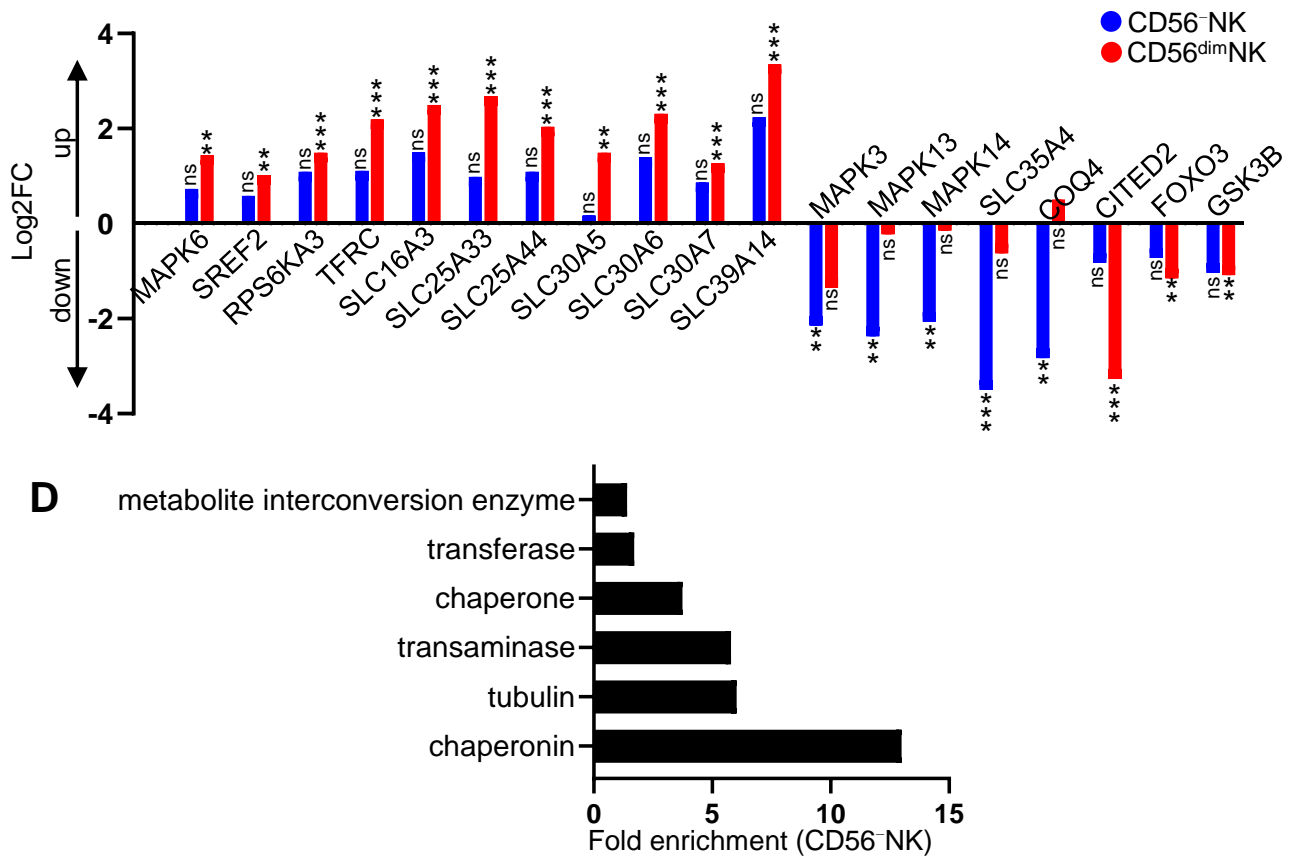

E metabolite interconversion enzyme nucleic acid metabolism protein RNA metabolism protein

RNA processing factor translational protein translation factor kinase modulator translation initiation factor chaperone aminoacyl-tRNA synthetase vesicle coat protein
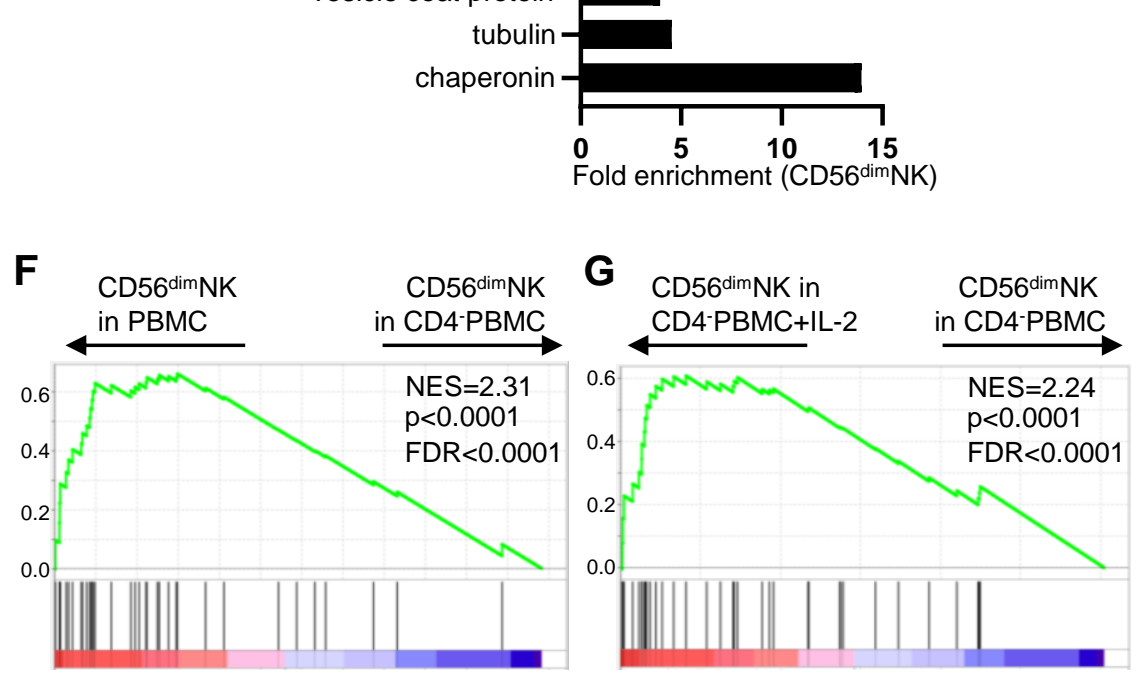

Row min Row max 

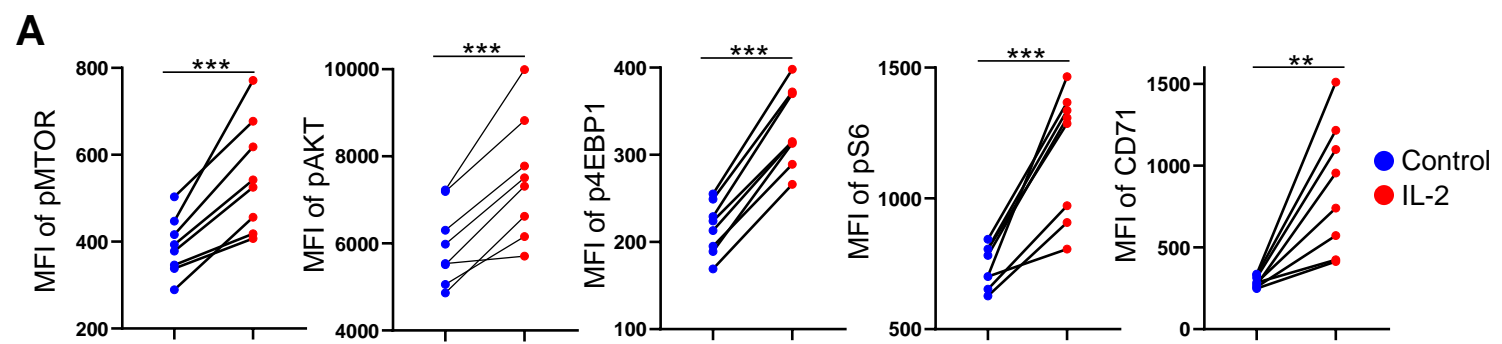

B
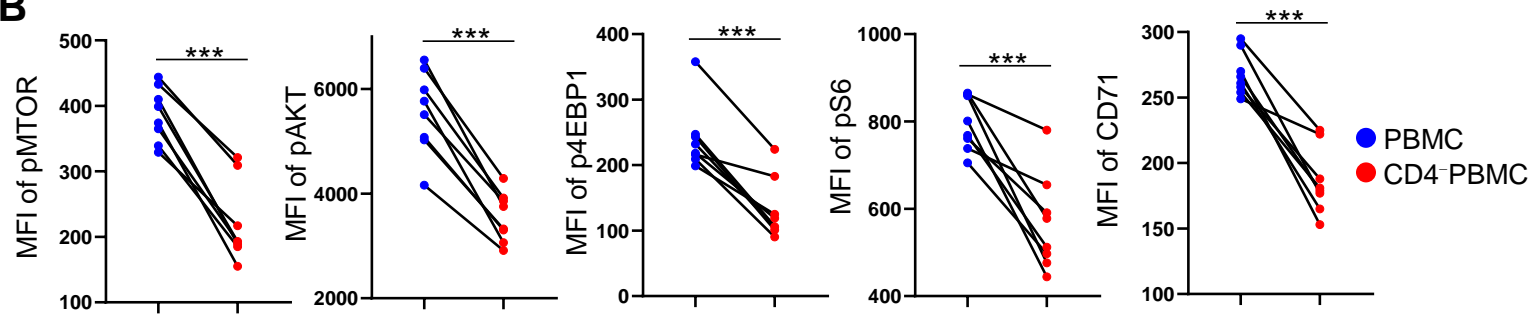

C

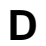

E
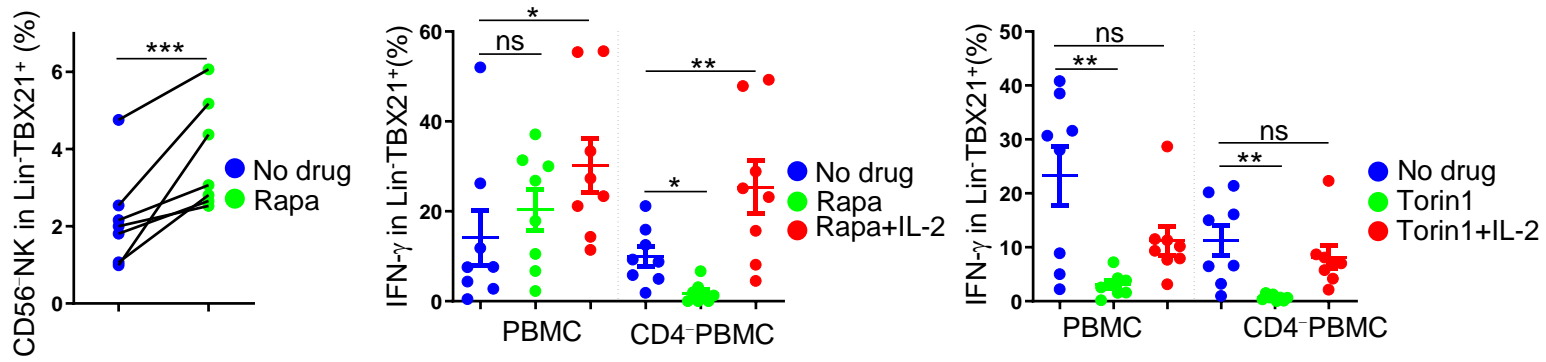